University of Konstanz

Department of Economics

\title{
Wage Floors, Imperfect Performance Measures, and Optimal Job Design
}

Jenny Kragl and Anja Schöttner

Working Paper Series

2012-36

http://www.wiwi.uni-konstanz.de/forschung/ 


\title{
Wage Floors, Imperfect Performance Measures, and Optimal Job Design*
}

\author{
Jenny Kragl ${ }^{\dagger}$ and Anja Schöttner ${ }^{\ddagger}$
}

December 14, 2012

\begin{abstract}
We analyze the effects of wage floors on optimal job design in a moral-hazard model with asymmetric tasks and imperfect aggregate performance measurement. Due to cost advantages of specialization, assigning the tasks to different agents is efficient. A sufficiently high wage floor, however, induces the principal to dismiss one agent or to even exclude tasks from the production process. Imperfect performance measurement always lowers profit under multitasking, but may increase profit under specialization. We further show that variations in the wage floor and the agents' reservation utility have significantly different effects on welfare and optimal job design.
\end{abstract}

JEL Classification: M51, M52, M54, D82, D86

Keywords: Job Design, Limited Liability, Minimum Wage, Moral Hazard, Multitasking, Performance Measurement

\footnotetext{
*We would like to thank Michael Burda, Guido Friebel, Oliver Gürtler, Manuela Hirsch, Ola Kvaløy, Jörg Oechssler, Andreas Roider, Patrick Schmitz, Wendelin Schnedler as well as three anonymous referees. We are also grateful for helpful comments and discussions at the 2011 meetings of the Royal Economic Society, Verein für Socialpolitik, Kolloquium zur Personalökonomie, the 11th Annual Meeting of the German Economic Association of Business Administration e.V., and at various research seminars. The first author gratefully acknowledges financial support by the DFG through grant DE 1169 and the second author through grant SFB/TR 15 .

${ }^{\dagger}$ Department of Governance \& Economics, EBS Universität für Wirtschaft und Recht, GustavStresemann-Ring 3, D-65189 Wiesbaden, Germany, e-mail: jenny.kragl@ebs.edu.

${ }^{\ddagger}$ Department of Economics, University of Konstanz, Postbox 144, D-78457 Konstanz, Germany, e-mail: anja.schoettner@uni-konstanz.de.
} 
"When the [minimum] wage went up on Sept. 1 he halved her hours. Meantime, full-timers have taken up that slack. Nowadays, one person sets up the registers, then starts the biscuits, then does assorted odd tasks before business picks up at lunch time. Mr. Isah freely concedes that people are working twice as hard for their modest raise."

\section{Wysocki Jr. (1997), The Wall Street Journal ${ }^{1}$}

\section{Introduction}

Production usually involves the completion of various tasks that differ in their value for the firm. The decision on how to optimally allocate these tasks to the workers of the firm is an important question in organizational design. Another major concern is how to incentivize workers to perform their tasks in the firm's interest. Typically, available performance measures only imperfectly reflect a worker's true contribution to firm value. This is particularly relevant if performance at each task cannot be measured separately. A careful design of reward schemes is then crucial to induce desired behavior (see, e.g., Kerr (1975)). The design of labor contracts is, however, not only guided by endogenous coordination and motivation issues but also by exogenous restrictions on wages such as minimum wages, liability limits, wealth constraints, and collective bargaining agreements. This paper takes a step towards a better understanding of optimal task allocation and incentive provision by studying the consequences of exogenous wage floors, differently productive tasks, and imperfect aggregate performance measurement for the job design problem of the firm. By considering these different aspects of employment relationships simultaneously, we differ from previous work on job design and incentive contracting and thus contribute to a more comprehensive characterization of optimal labor contracts and organizational design.

We present a moral-hazard model where two tasks jointly affect firm value and an imperfect performance measure. The tasks may be asymmetric, i.e., they make different contributions to firm value. The firm (principal) can choose between three job designs; multitasking, specialization, and task exclusion. Under multitasking, the tasks are assigned to one job and thus carried out by a single worker (agent). Specialization means that each task is performed by a different agent. Finally, under task exclusion, just one of the tasks is assigned to an agent while the other task is not carried out. ${ }^{2}$ Our model is designed to capture a situation where specialization is optimal in the absence of wage

\footnotetext{
${ }^{1}$ Wysocki Jr. (1997), p. A1, on the effects of the 1996 minimum wage increase in the fast-food sector for the case of a Popeyes Chicken \& Biscuits restaurant in West Philadelphia. Mr. Isah is the store manager.

${ }^{2}$ Task exclusion requires the principal to be able to prevent an agent from engaging in a task that is not assigned to his job and not performed by another agent either. This can be achieved, for instance, by not granting the agent access to indispensable task-specific tools (see also Ratto and Schnedler (2008)).
} 
floors. Specifically, specialization dominates the other job designs for two reasons. First, division of labor lowers total effort costs because tasks are substitutes in an agent's cost function. ${ }^{3}$ Second, specialization allows the principal to tailor incentives to the different tasks by offering workers individual rewards contingent on the joint performance measure. To illustrate our model, consider a fast-food chain and the two tasks 'selling' and 'cleaning' in each individual store. Both tasks contribute to the value of the chain and also affect the store's divisional profit, which is, say, the only available performance measure. While cleanliness of the store has a positive impact on divisional profit, the effect on total firm value is more significant because there are externalities of the cleanliness of one restaurant on other stores. Hence, divisional profit reflects the tasks' contribution to firm value only imperfectly. If a single worker is responsible for both tasks, incentives based on divisional profit will distort the worker's attention towards the selling task. By contrast, with specialization the firm can vary the strength of incentives across workers and thereby induce efficient effort in both tasks. Furthermore, total effort costs are lower under specialization because a worker who is already responsible for selling finds it harder to also clean. A specialized job design thus maximizes firm profits when no wage floor exists. The firm then even induces the first-best effort allocation across tasks and earns the first-best profit.

In this framework, we derive four main results. Firstly, if a lower bound on wages is introduced, the separation of tasks becomes relatively more expensive to the firm. As soon as the wage floor becomes binding, providing efficient incentives entails rent payments to workers. The firm then immediately responds by distorting effort incentives and, at some point, even abandons specialization. Notably, the firm gives up specialization even before the wage floor exceeds the workers' reservation utility.

Secondly, we show that the level of the wage floor at which the firm abandons efficient incentives and thus does no longer realize the first-best profit varies with the quality of the performance measure. In particular, under specialization with asymmetric tasks, the firm benefits from an imperfect performance measure that overemphasizes the less productive task relative to firm value. Such a performance measure allows the firm to reduce total rent payments by increasing the incentive responsiveness of the worker performing the less productive task. In our example of a fast-food chain, suppose that 'selling' more strongly affects firm value than 'cleaning'. A restaurant's cleanliness, however, may have a stronger impact on customer satisfaction than the effectiveness of the selling process. According to our result, basing the workers' incentives on a survey on customer satisfaction would allow the firm to sustain first-best profits for higher wage floors, an advantage that might outweigh the cost of surveying customers. Under multitasking, however, the

\footnotetext{
${ }^{3}$ The main results of the paper continue to hold when tasks are complements, see Section 4.2.
} 
firm's profit is always increasing in the quality of the performance measure. ${ }^{4}$ Imperfect performance measurement can thus be beneficial in our framework only when the firm employs specialization, tasks are asymmetric, and a wage floor exists.

Thirdly, when the wage floor is so high that the principal hires only one agent, she may exclude the less productive task from the agent's job. Restricting the job to the more important task rules out a distortion of effort across tasks, which is inevitable under multitasking. This advantage outweighs the loss from non-execution of the less productive task when the quality of the performance measure is sufficiently poor, multitasking strongly diminishes productivity due to higher effort costs, or the wage floor for a multitasking agent is rather large (e.g., due to long working hours).

Fourthly, we show that exogenous changes in market conditions such as the workers' reservation utilities (e.g., unemployment benefits) and wage floors (e.g., minimum wages) usually have opposing effects on overall welfare and organizational design. Opposing effects on welfare already arise when the job design is fixed. The reason is that the two parameters influence the firm's incentive contracting problem in fundamentally different ways: The firm may respond to an increase in the reservation utility by enhancing incentives, leading to higher welfare. By contrast, an increase in the wage floor always entails weakly inferior incentive schemes. When the organizational design is endogenous, opposing effects persist: Higher reservation utilities usually increase total welfare, help sustain efficient incentives, and raise the workers' income. By contrast, higher wage floors typically diminish total surplus and make the establishment of an efficient job regime less likely.

Our findings bear relevance for a large variety of jobs, namely those where wage floors and performance pay coexist. For example, managers frequently receive substantial bonuses in case of success but are protected by limited liability in case of failure. In the low-wage sector, waiters, retail workers, or sales people are often protected by a legal minimum wage but also obtain incentive pay. ${ }^{5}$ As suggested by the introductory quotation on Popeyes Chicken \& Biscuits, anecdotal evidence from several low-wage employers in the fast-food sector is consistent with our model's predictions. Indeed, in response to minimum wage increases, employers cut hours, increase workloads, and assign more tasks to a single worker (see Wysocki Jr. (1997), Duff (1996)). Underlining that, along with "the harsh business environment", such developments may have a clearly negative impact on firm value, Wysocki Jr. (1997) notes that "crew hours were cut back, and cleanliness suffered", while Popeyes' store manager is worried that the "[q]uality of work will fall". This supports our prediction that wage floors may lead to the negligence of 'less important

\footnotetext{
${ }^{4}$ In the absence of wage floors, this has been shown by, e.g., Baker (2002) and Gibbons (2005).

${ }^{5}$ For example, fast-food companies such as McDonald's and Popeyes Chicken \& Biscuits usually implement incentive-based performance programs (see, e.g., Job-Applications.com (2012), Hoyland (2010a,b), or McDonald's (2012)).
} 
tasks' such as cleaning compared to cooking. Moreover, several empirical studies show that a minimum wage can have a significant negative (positive) impact on job-finding (job-loss) probabilities, which is in line with our finding that a firm may offer fewer jobs in response to a minimum wage increase. ${ }^{6}$

The present paper brings together important aspects of the literature on job design and that on wage floors. For more than two decades, economists have been concerned with incentive distortions and inefficiencies that result from limited liability in principal-agent models. ${ }^{7}$ We are, however, the first to introduce liability limits or, more generally speaking, wage floors in a multitasking setting with imperfect performance measures. The basic rationale for distorted effort incentives under multitasking was first presented by Holmström and Milgrom (1991) and Baker (1992). ${ }^{8}$ Moreover, Holmström and Milgrom (1991) already suggested that splitting tasks into different jobs can prevent the misallocation of effort. This idea was later formalized by Ratto and Schnedler (2008). We complement the foregoing literature by highlighting that wage floors may diminish or even eliminate the advantage of separating tasks.

Itoh (1994) also analyzes optimal job design in a production process with a joint performance measure for two tasks that are cost substitutes. In contrast to our model, agents are risk averse, wage floors are absent, tasks are equally productive, and the performance measure is perfect. ${ }^{9}$ Itoh (1994) shows that multitasking is preferred to specialization when the degree of substitutability between tasks is sufficiently low because then the effect of paying a risk premium to only one agent dominates. Along similar lines, we find that specialization becomes too costly for the principal when the wage floor is so high that specialized agents would earn rents under any incentive scheme. However, it is worth noting that, in our model, the principal may abandon specialization even before wage floors lead to worker rents. Moreover, by including asymmetric tasks and imperfect performance measurement in the model, we are able to derive novel results on the usefulness of imperfect performance measures and the optimality of task exclusion.

The literature provides further reasons as to why broad task assignments may be optimal. Zhang (2003) and Hughes, Zhang, and Xie (2005) demonstrate that complemen-

\footnotetext{
${ }^{6}$ Positive effects on job-loss probabilities of affected workers in the US have been reported by, e.g., Currie and Fallick (1996) and Zavodny (2000) and by Abowd, Kramarz, and Margolis (1999) for both French and US workers. Investigating the 1987 minimum wage increase for Portuguese teenagers, Portugal and Cardoso (2001) report that minimum wages reduce the probability that firms hire workers from the affected group.

${ }^{7}$ Important contributions include Sappington (1983), Park (1995), Kim (1997), Demougin and Fluet (2001), Lewis and Sappington (2000, 2001), and Jewitt, Kadan, and Swinkels (2008).

${ }^{8}$ Building upon these seminal papers, multitasking problems are also analyzed by, e.g., Feltham and Xie (1994), Datar, Kulp, and Lambert (2001), Baker (2002), and Schnedler (2008, 2010).

${ }^{9}$ In a setting similar to Itoh (1994), Itoh (2001) considers imperfect performance measurement as an extension. However, in contrast to us, he discusses how this affects the principal's decision to delegate one or both of two tasks to an agent, where the non-delegated task is performed by the principal herself. In our model, the principal cannot perform any task herself.
} 
tarities between tasks may lead to task bundling, which is in line with the results of our model extension to complementary tasks. In a multitasking setting with both explicit and relational incentive contracting, Schöttner (2008) shows that broader task assignments may enhance relational employment contracts. Laux (2001) and Schmitz (2005) study pros and cons of task bundling under limited liability when individual (task-dependent) performance measures exist. Similar to our first result, Laux (2001) shows that the assignment of multiple projects to a single manager reduces managerial rents and thus expected wage costs. Schmitz (2005) considers the organization of a project that consists of two stages, at each of which a task has to be performed. Incentive considerations can explain the optimality of either separation or integration of tasks.

Finally, our paper is also related to neoclassical labor market models (see, e.g., Boeri and van Ours (2008)), which explore minimum wages at an aggregate level. In competitive markets, these models predict negative effects of minimum wages on aggregate employment while conclusions are ambiguous for non-competitive labor markets. ${ }^{10}$ In a recent study, Amine and Lages Dos Santos (2011) analyze public policies in a matching model with heterogeneous workers and endogenous choice of the production technology. Abstracting from incentive problems and keeping the number of jobs in a firm fixed, they find that firms respond to an increase in the minimum wage or unemployment benefit by making jobs more complex and recruiting more skilled workers. Our paper complements these aggregate models by offering novel insights based on incentive considerations and job design at the firm level.

The remainder of the paper proceeds as follows. The next section introduces the model and the first-best job design. In Section 3, we derive our results on optimal job design. After discussing the feasible effort allocations under the different job regimes in Section 3.1, we derive optimality conditions for specialization (Section 3.2), multitasking, and task exclusion (Section 3.3). Subsequently, we analyze the consequences of variations in the wage floor and the reservation utility on welfare and organizational design in Section 4.1 and discuss implications for labor market regulation. In Section 4.2, we extend our model to complementary tasks and also consider the case where the principal cannot exclude a task from an agent's job. Finally, Section 5 concludes. All proofs are relegated to the Appendix.

\section{The Model}

Production Technology and Information Structure We consider a production process that requires the completion of two tasks. Effort in task $i(i=1,2)$ is denoted by

\footnotetext{
${ }^{10}$ See Manning $(2003,2010)$ for a comprehensive discussion of imperfect competition in labor markets.
} 
$e_{i} \geq 0$. Effort $e_{i}$ reflects the diligence exercised by the worker who carries out task $i$. A task cannot be split between different workers. ${ }^{11}$ The effort levels' joint contribution to total firm value is denoted by $Y$ and is either high or low, $Y \in\{0,1\}$. The probability for $Y=1$ is given by

$$
\operatorname{Pr}\left[Y=1 \mid e_{1}, e_{2}\right]=\min \left\{f_{1} e_{1}+f_{2} e_{2}, 1\right\}
$$

Here, $f_{i}>0$ is the marginal impact of effort in task $i$ on the expected contribution to firm value. In addition, there is a joint performance measure $P \in\{0,1\}$ for both tasks, with

$$
\operatorname{Pr}\left[P=1 \mid e_{1}, e_{2}\right]=\min \left\{g_{1} e_{1}+g_{2} e_{2}, 1\right\}
$$

Thus, $g_{i}>0$ is the marginal impact of effort in task $i$ on the expected value of the performance measure. Since both $f_{i}$ and $g_{i}$ are positive, increasing effort in either task raises the expected realization of both firm value and performance measure. However, because in general $f_{i} \neq g_{i}$, a task's true productivity differs from its impact on the performance measure. ${ }^{12}$ For ease of exposition, we introduce vector notation and define $f=\left(f_{1}, f_{2}\right)^{T}$, $g=\left(g_{1}, g_{2}\right)^{T}$, and $e=\left(e_{1}, e_{2}\right)^{T}$. All vectors are column vectors and superscript $T$ denotes transpose.

The firm owner observes $f_{i}$ and $g_{i}$, and the workers observe (at least) $g_{i}(i=1,2)$ before contracting takes place. A worker's effort is his private information, implying a moralhazard problem and the need for the principal to provide effort incentives. However, the tasks' contribution to firm value, $Y$, is not observable and therefore not contractible. ${ }^{13}$ Incentive contracts therefore have to rely on the performance measure $P$, which is observed by the firm owner and the workers and is also verifiable by a court of law.

According to our specification, $Y$ and $P$ are subject to exogenous random influences. We do not impose any restriction on the underlying type of uncertainty. In particular, the random variables $Y$ and $P$ may be (imperfectly) correlated. For short, we refer to $Y$ as firm value in the remainder of the paper.

Job Design and Timing The firm owner (principal) cannot perform any of the tasks herself. For execution of the tasks, she can choose between three job designs: specialization,

\footnotetext{
${ }^{11}$ For instance, in a fast-food restaurant, only one person can operate a particular cash register or clean a particular table.

${ }^{12}$ We could also assume that one of the tasks, say task 1 , is indispensable for realizing a high firm value and/or a high performance measure, i.e., $\operatorname{Pr}\left[Y=1 \mid e_{1}=0, e_{2}\right]=0$ and/or $\operatorname{Pr}\left[P=1 \mid e_{1}=0, e_{2}\right]=0$ for all $e_{2} \geq 0$, whereas (1) and (2) apply if $e_{1}>0$ and $e_{2} \geq 0$. For example, task 1 is indispensable to obtain $P=1$ if this task is a production task and $P=1$ means that the good has been produced (while task 2 could be the maintenance of the asset required for production). Assuming that task 1 is indispensable would lead to exactly the same results as the above specification because our optimal contract will always induce strictly positive effort in task 1 .

${ }^{13}$ For example, it is not observable how the activities in a particular fast-food restaurant contribute to the value of the whole chain.
} 
task exclusion, and multitasking. Under specialization, the principal employs two workers (agents), each carrying out one task. Otherwise, the principal hires only one agent who either performs only one task (task exclusion) or both tasks (multitasking). In the former case, the agent is forbidden to exert effort in the excluded task and, consequently, this task is not performed at all. ${ }^{14}$

Timing is as follows. First, the principal determines the job design. If she hires only one agent, she offers this agent an employment contract. The contract specifies the task assignment (either both tasks, or only task 1, or only task 2 ), a fixed wage $s$, and a bonus $b$ to be paid if the performance measure is favorable, i.e., if $P=1$. The agent thus receives $s$ if $P=0$ and $s+b$ if $P=1$. If the agent accepts the contract, he exerts effort. Then, $P$ is realized and payments are made.

By contrast, under specialization, the principal proposes each of the two agents a separate contract. For simplicity, an agent is identified with the task $i$ he is supposed to perform. Thus, the contract for agent $i$ specifies that he will carry out task $i$, receive a fixed wage $s_{i}$, and a bonus $b_{i}$ if $P=1$. Given that both agents accept the contract, they simultaneously exert effort in their tasks. Afterwards, $P$ is realized and the agents are paid.

Agents' Characteristics Agents are homogeneous and risk neutral. An agent's cost of exerting effort is

$$
c\left(e_{1}, e_{2}\right)=\frac{1}{2}\left(c_{1} e_{1}^{2}+c_{2} e_{2}^{2}\right)+c_{12} e_{1} e_{2}=\frac{1}{2} e^{T} C e,
$$

where

$$
C=\left(\begin{array}{ll}
c_{1} & c_{12} \\
c_{12} & c_{2}
\end{array}\right),
$$

$c_{1}, c_{2}>0$, and $c_{12} \in\left[0, \sqrt{c_{1} c_{2}}\right) .{ }^{15}$ When $c_{12}$ is strictly positive, the tasks compete for the agent's attention in the sense that an agent who is already responsible for one task finds it harder to engage in another one, i.e., tasks are substitutes. Consequently, for any given pair of positive effort levels $\left(e_{1}, e_{2}\right)$, total effort costs are lower under specialization than under multitasking. The opposite case of complementary tasks is discussed in Section 4.2. We assume that $f, g$, and $C$ are such that the probabilities in (1) and (2) remain strictly below one at the first-best and second-best solution. ${ }^{16}$ An agent accepts the principal's job offer if it guarantees him an expected wage payment net of effort costs of at least

\footnotetext{
${ }^{14}$ We thus assume that the principal can enforce that a task is not executed (compare Footnote 2 in the Introduction). If this was not possible, however, our analysis would proceed in a very similar way. We discuss this case in Section 4.2.

${ }^{15}$ The restriction $c_{12}<\sqrt{c_{1} c_{2}}$ ensures that the cost function is strictly convex and the matrix $C$ is positive definite.

${ }^{16}$ Hence, from now on we will simply write $\operatorname{Pr}\left[Y=1 \mid e_{1}, e_{2}\right]=f_{1} e_{1}+f_{2} e_{2}=f^{T} e$ and $\operatorname{Pr}\left[P=1 \mid e_{1}, e_{2}\right]=$ $g_{1} e_{1}+g_{2} e_{2}=g^{T} e$.
} 
$u \geq 0$, i.e., $u$ denotes an agent's reservation utility.

Wage Floors Due to exogenous restrictions, the wage of an agent must meet or exceed some given wage floor in each state of the world. The applicable wage floor may depend on the number of tasks assigned to the agent. If the agent performs only one task, this wage floor is $w$. We allow $w$ to take values from the interval $[-\infty, \infty)$. In case $w \geq 0$, we can interpret $w$ as a minimum wage. By contrast, if $-\infty<w<0$, the firm can extract payments from the agent, but the latter is protected by limited liability (or has limited wealth). Finally, the case $w=-\infty$ corresponds to a situation without any restrictions on wage payments. If the agent performs two tasks, his wage floor is denoted $w^{m} \geq w$. The case $w^{m}=w$ applies when the wage floor reflects a liability limit or is due to an hourly or monthly minimum wage but an agent's working hours are independent of his task assignment. ${ }^{17}$ If, however, an agent's working hours can be reduced when he performs only one task, a wage floor dictated by an hourly minimum wage is higher under multitasking than under single-task assignments, i.e., $w^{m}>w$.

First-best Job Design As a benchmark, we now characterize the optimal job design if effort is contractible. To do so, we derive the effort levels that maximize expected firm value net of effort costs under all possible job regimes and compare the resulting profits. First consider the case of specialization. The optimal effort levels then are

$$
e^{S^{*}}=\left(e_{1}^{S^{*}}, e_{2}^{S^{*}}\right)^{T}=\arg \max _{e_{1}, e_{2}} f_{1} e_{1}+f_{2} e_{2}-\frac{1}{2}\left(c_{1} e_{1}^{2}+c_{2} e_{2}^{2}\right)-2 u=\left(\frac{f_{1}}{c_{1}}, \frac{f_{2}}{c_{2}}\right)^{T}
$$

yielding the profit

$$
\pi^{S^{*}}=\frac{1}{2}\left(\frac{f_{1}^{2}}{c_{1}}+\frac{f_{2}^{2}}{c_{2}}\right)-2 u
$$

To ensure that considering specialization is worthwhile, we assume that $\frac{1}{2} \frac{f_{i}^{2}}{c_{i}}-u>0$, $i=1,2$, implying that each agent's net contribution to firm value is positive. For the further analysis, it will prove helpful to define the vector

$$
f^{s}:=\left(f_{1} / \sqrt{c_{1}}, f_{2} / \sqrt{c_{2}}\right)^{T}
$$

Intuitively, $f^{s}$ reflects the tasks' net productivities under specialization, i.e., the tasks' productivities $f$ corrected by the cost differences across tasks. Without loss of generality we assume that task 1 has a weakly higher net productivity, i.e., $f_{1} / \sqrt{c_{1}} \geq f_{2} / \sqrt{c_{2}}$, and is thus more important to the firm than task 2 . We say that the tasks are asymmetric when

\footnotetext{
${ }^{17}$ The latter case can incorporate a situation where an agent's nominal working hours (i.e., the stipulated working time during which he must be present at the workplace) do not vary but the time he is indeed performing his tasks or his working pace may change under multitasking.
} 
the former inequality is strict.

If the principal hires only one agent and assigns both tasks to him, optimal effort is

$$
e^{M^{*}}=\left(e_{1}^{M^{*}}, e_{2}^{M^{*}}\right)=\arg \max _{e_{1}, e_{2}} f^{T} e-\frac{1}{2} e^{T} C e-u
$$

We assume that both effort levels $e_{1}^{M^{*}}, e_{2}^{M^{*}}$ are strictly positive, i.e., $c_{12}$ is not too large. This immediately implies that task exclusion cannot be first-best. The surplus-maximizing effort levels with one agent thus are

$$
e^{M^{*}}=C^{-1} f=\left(\frac{c_{2} f_{1}-c_{12} f_{2}}{c_{1} c_{2}-c_{12}^{2}}, \frac{c_{1} f_{2}-c_{12} f_{1}}{c_{1} c_{2}-c_{12}^{2}}\right)^{T},
$$

yielding the profit

$$
\pi^{M^{*}}=\frac{1}{2} f^{T} C^{-1} f-u=\frac{1}{2} \frac{c_{2} f_{1}^{2}+c_{1} f_{2}^{2}-2 c_{12} f_{1} f_{2}}{c_{1} c_{2}-c_{12}^{2}}-u
$$

which we assume to be positive. Here, $C^{-1}$ denotes the inverse of $C$, which exists because $C$ is positive definite.

Compared to multitasking, specialization has the advantage of lower total effort costs, but the disadvantage that two agents have to be compensated for their forgone outside option $u$. In line with one of the main arguments for specialization, namely the cost advantage through the division of labor, we want to focus on situations where the benefits of specialization outweigh its costs, i.e., $\pi^{S^{*}} \geq \pi^{M^{*}}$. Such a situation occurs if $c_{12}$ is sufficiently large relative to $u$ and includes the special case $c_{12}=u=0$, where the principal is indifferent between specialization and multitasking in the first-best world. We thus make the following assumption.

Assumption 1 The first-best effort levels and the first-best profit are $e^{S^{*}}$ and $\pi^{S^{*}}$, respectively. Thus, specialization weakly dominates both multitasking and task exclusion when effort is contractible.

Assumption 1 will imply that specialization is also the second-best job design when wage floors are sufficiently low, which greatly simplifies the exposition of the paper. ${ }^{18}$ Restricting attention to $\pi^{S^{*}} \geq \pi^{M^{*}}$ and thus $c_{12} \geq 0$ is, however, not a necessary ingredient for any of the following results as we show in Section 4.2.

\footnotetext{
${ }^{18}$ Specifically, it allows us to postpone the analysis of multitasking to Section 3.3.
} 


\section{Optimal Job Design}

In this section, we derive the optimal allocation of tasks in the presence of moral hazard. After presenting some preliminary results in the first subsection, we subsequently derive optimality conditions for specialization, multitasking, and task exclusion.

\subsection{Feasible Effort Allocations under the Different Job Designs}

We first derive two preliminary results concerning the set of feasible effort levels, i.e., the effort allocation that the principal can induce under the different job regimes. To do so, we consider the stage of the game where, given the job design and employment contract(s), effort is chosen by the agent(s).

Under specialization, agent $i$ chooses his effort $e_{i}$ to maximize his expected wage net of effort costs, taking the effort level of worker $j$ as given, i.e.,

$$
e_{i}=\arg \max _{\hat{e}_{i}} s_{i}+\left(g_{i} \hat{e}_{i}+g_{j} e_{j}\right) b_{i}-\frac{1}{2} c_{i} \hat{e}_{i}^{2}=\frac{g_{i}}{c_{i}} b_{i}, \quad i=1,2
$$

The principal can thus induce every arbitrary pair of effort levels $\left(e_{1}, e_{2}\right)$ by offering the bonuses $b_{i}=\frac{c_{i}}{g_{i}} e_{i}$. This is the case even though $P$ is not identical to firm value $Y$, implying that the agents care about the realization of $P$ rather than $Y$. However, this is not detrimental because the principal can pay agents individual bonuses, which allows to fine-tune incentives to the different tasks in any desired way.

Lemma 1 Under specialization, the principal can induce each arbitrary pair of effort levels. In particular, the first-best effort allocation $e^{S^{*}}$ is always feasible.

By contrast, under multitasking, it is not possible to provide individual incentives for the two tasks. Assuming $C^{-1} g>0$ to ensure an interior solution to the agent's problem, the agent chooses the effort levels

$$
e=\arg \max _{\hat{e}} s+g^{T} \hat{e} \cdot b-\frac{1}{2} \hat{e}^{T} C \hat{e}=b \cdot C^{-1} g .
$$

Hence, the principal is extremely restricted in the set of effort levels she is able to induce. We obtain the following Lemma, which replicates a result from Proposition 1 in Schöttner (2008).

Lemma 2 Under multitasking, the principal can induce only those effort levels $e$ that are multiples of the vector $C^{-1} g$. In particular, the surplus-maximizing effort allocation $e^{M^{*}}$ is feasible if and only if $f=\lambda g$ for some real number $\lambda>0$ or, equivalently, $\frac{f_{1}}{f_{2}}=\frac{g_{1}}{g_{2}}$. 
If $f_{1} / f_{2}=g_{1} / g_{2}$, we call the performance measure perfect and otherwise imperfect. In the latter case, the principal cannot induce the surplus-maximizing effort levels under multitasking because there is no bonus that makes the agent internalize the tasks' true contribution to firm value. Task exclusion, on the other hand, forces the agent to focus on only one task, thereby ruling out a misallocation of effort across tasks. This allows the principal to induce an arbitrary effort level in one task which comes, however, at the cost of zero effort in the other task. Thus, when effort is non-observable and the performance measure is imperfect, specialization has a further important advantage over multitasking and task exclusion: Specialization does not restrict the set of implementable effort levels. ${ }^{19}$

\subsection{Optimality Conditions for Specialization and the Benefit of Imper- fect Performance Measures}

In this subsection, we first determine the circumstances under which the principal finds it optimal to induce first-best effort under specialization, which provides us with a sufficient condition for the optimality of this job design. This condition enables us to discuss how the implementation of the first-best solution is affected by the quality of the performance measure. Moreover, we derive a sufficient condition for the principal to abandon specialization.

Anticipating the agents' effort choices under a given contract, as described by (11), the principal's optimization problem under specialization is:

$$
\begin{gathered}
\max _{\substack{e, s_{i}, b_{i} \\
i=1,2}} f^{T} e-s_{1}-s_{2}-g^{T} e \cdot\left(b_{1}+b_{2}\right) \\
\text { s.t. } \quad e_{i}=\frac{g_{i}}{c_{i}} b_{i}, \quad i=1,2 \\
s_{i}+g^{T} e \cdot b_{i}-\frac{1}{2} c_{i} e_{i}^{2} \geq u, \quad i=1,2 \\
s_{i} \geq w, \quad i=1,2 \\
s_{i}+b_{i} \geq w, i=1,2
\end{gathered}
$$

When maximizing expected firm value minus wage costs, the principal has to take into account the agents' incentive compatibility and participation constraints, $\left(\mathrm{IC}_{S}\right)$ and $\left(\mathrm{PC}_{S}\right)$, respectively. Moreover, the wage-floor constraints $\left(\mathrm{WC}_{S}\right)$ and $\left(\mathrm{WC}_{S}^{\prime}\right)$ must be satisfied. To simplify the principal's problem, first note that we can drop the constraints $s_{i}+b_{i} \geq w$ because from $\left(\mathrm{IC}_{S}\right)$ it is clear that we can focus on non-negative bonuses. Furthermore, we can use $\left(\mathrm{IC}_{S}\right)$ to replace $e_{i}$. We then obtain from agent $i$ 's participation and wage-floor

\footnotetext{
${ }^{19}$ This observation is related to Propositions 1 and 2 in Ratto and Schnedler (2008), who show that the principal can induce a certain desired effort allocation across two tasks only when she hires two agents.
} 
constraint that, for given bonuses $b_{i}$ and $b_{j}$, his optimal fixed wage satisfies

$$
s_{i}=\max \left\{u-\frac{1}{2} \frac{g_{i}^{2}}{c_{i}} b_{i}^{2}-\frac{g_{j}^{2}}{c_{j}} b_{j} b_{i}, w\right\}, i, j=1,2, i \neq j .
$$

To shorten notation, we now define a vector $g^{s}$ analogous to $f^{s}$,

$$
g^{s}:=\left(g_{1} / \sqrt{c_{1}}, g_{2} / \sqrt{c_{2}}\right)^{T} .
$$

Hence, after substituting $s_{i}$, the principal's optimization problem becomes:

$$
\begin{aligned}
\max _{b_{1}, b_{2}}\left[f_{1}^{s} g_{1}^{s} \cdot b_{1}+f_{2}^{s} g_{2}^{s} \cdot b_{2}\right. & -\max \left\{u+\frac{1}{2}\left(g_{1}^{s}\right)^{2} b_{1}^{2}, w+\left(g_{1}^{s}\right)^{2} b_{1}^{2}+\left(g_{2}^{s}\right)^{2} b_{1} b_{2}\right\} \\
-\max & \left.\left\{u+\frac{1}{2}\left(g_{2}^{s}\right)^{2} b_{2}^{2}, w+\left(g_{2}^{s}\right)^{2} b_{2}^{2}+\left(g_{1}^{s}\right)^{2} b_{1} b_{2}\right\}\right]
\end{aligned}
$$

The term $f_{1}^{s} g_{1}^{s} \cdot b_{1}+f_{2}^{s} g_{2}^{s} \cdot b_{2}$ is the expected firm value for given bonuses $b_{1}$ and $b_{2}$. The next expression is the principal's expected wage payment to agent 1 . If the bonuses are such that $u+\frac{1}{2}\left(g_{1}^{s}\right)^{2} b_{1}^{2} \geq w+\left(g_{1}^{s}\right)^{2} b_{1}^{2}+\left(g_{2}^{s}\right)^{2} b_{1} b_{2}$, then the fixed payment $s_{1}$ can be chosen such that agent 1's participation constraint is binding. Otherwise, the agent earns a rent under the bonuses $b_{1}$ and $b_{2}$, i.e., his expected wage payment net of effort costs exceeds his reservation utility. Importantly, in the latter case, agent 1's expected payment also depends on the bonus paid to agent 2. The reason is that agent 2's incentives affect agent 1's probability of earning his own bonus: The higher $b_{2}$, the harder agent 2 works. Consequently, the probability that the agents' joint performance measure $P$ is favorable rises and, thus, agent 1's expected bonus payment also increases. The part of agent 1's expected payment that results from agent 2 's effort is exactly $\left(g_{2}^{s}\right)^{2} b_{1} b_{2}$ because

$$
\operatorname{Pr}\left[P=1 \mid e_{1}=0, e_{2}\right] \cdot b_{1}=g_{2} e_{2} \cdot b_{1}=\left(g_{2}^{s}\right)^{2} b_{2} \cdot b_{1},
$$

where the last equation follows from the incentive-compatibility constraints $\left(\mathrm{IC}_{S}\right)$. An analogous explanation holds for agent 2's expected wage, which is given by the term in the second line of $\left(\mathrm{II}_{S}\right)$.

Let $\pi^{S}(u, w)$ denote the principal's profit under the solution to problem $\left(\mathrm{II}_{S}\right)$. Using $\left(\mathrm{IC}_{S}\right)$, we can rewrite $\left(\mathrm{II}_{S}\right)$ as a function of effort, which will be useful for the further analysis. We thus obtain:

$$
\begin{array}{r}
\pi^{S}(u, w)=\max _{e_{1}, e_{2}}\left[f_{1} e_{1}+f_{2} e_{2}-\max \left\{u+\frac{1}{2} c_{1} e_{1}^{2}, w+c_{1} e_{1}^{2}+c_{1} \frac{g_{2}}{g_{1}} e_{1} e_{2}\right\}\right. \\
\left.-\max \left\{u+\frac{1}{2} c_{2} e_{2}^{2}, w+c_{2} e_{2}^{2}+c_{2} \frac{g_{1}}{g_{2}} e_{1} e_{2}\right\}\right]
\end{array}
$$


Figure 1 depicts whether the principal has to pay rents to agent 1 and 2 , respectively, for inducing a given effort pair $\left(e_{1}, e_{2}\right)$. The figure is plotted for the case $g_{1}=g_{2}, c_{1}=c_{2}=1$, and $w<u$. If the effort pair belongs to area $A_{1}$, then no agent earns a rent. ${ }^{20}$ In area $A_{2}$, agent 1 obtains a rent but not agent 2 , whereas area $A_{3}$ corresponds to the opposite case. Finally, in area $A_{4}$, both agents earn rents. As $w$ increases and, consequently, $u-w$ decreases, $A_{4}$ becomes larger relative to the other areas. Moreover, if $u \leq w$, then $A_{1}$, $A_{2}$, and $A_{3}$ disappear. Thus, if the wage floor is at least as high as the reservation utility, both agents earn a rent for every pair of positive effort levels.

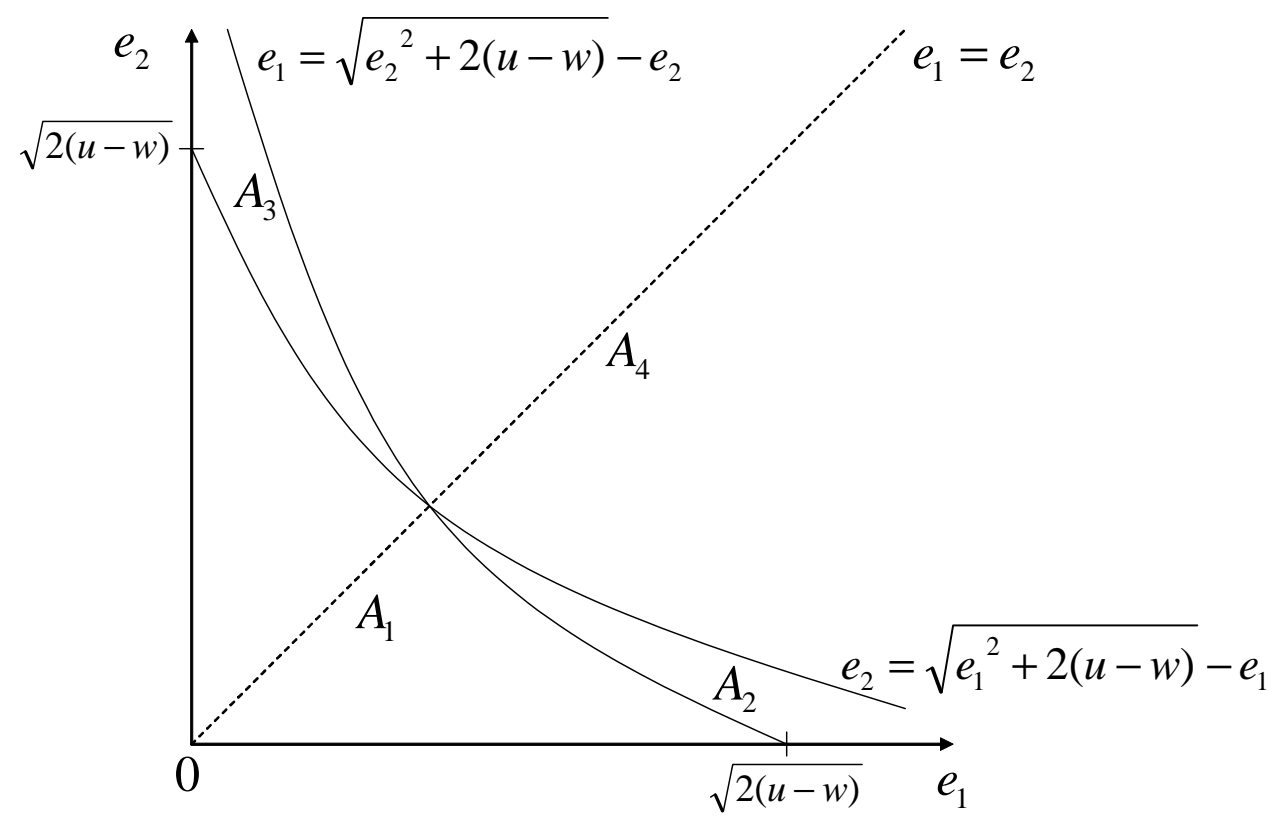

Figure 1: Workers' rents under specialization for given effort levels $\left(e_{1}, e_{2}\right)$.

Proposition 1 characterizes the circumstances under which specialization leads to the first-best solution.

Proposition 1 The principal induces the first-best effort levels $e^{S^{*}}$ and obtains the firstbest profit $\pi^{S^{*}}$ under specialization if and only if $w \leq u-R$, where

$$
R:=\max \left\{\frac{1}{2}\left(f_{1}^{s}\right)^{2}+\frac{g_{2}^{s}}{g_{1}^{s}} f_{1}^{s} f_{2}^{s}, \frac{1}{2}\left(f_{2}^{s}\right)^{2}+\frac{g_{1}^{s}}{g_{2}^{s}} f_{1}^{s} f_{2}^{s}\right\}
$$

\footnotetext{
${ }^{20}$ Define $q:=\frac{g_{2}}{g_{1}}$. From $\left(\mathrm{III}_{S}\right)$, agent 1 does not earn a rent if $u+\frac{1}{2} e_{1}^{2} \geq w+e_{1}^{2}+q e_{1} e_{2} \Leftrightarrow$ $\sqrt{q^{2} e_{2}^{2}+2(u-w)}-q e_{2} \geq e_{1}$. Analogously, agent 2 does not earn a rent if $\sqrt{q^{-2} e_{1}^{2}+2(u-w)}-q^{-1} e_{1} \geq e_{2}$.
} 
Consequently, $w \leq u-R$ is a sufficient condition for specialization being the optimal job design.

Inequality $(\mathrm{FB})$ ensures that $w$ is such that the principal does not need to pay rents for making the agents exert first-best effort, i.e., $e^{S^{*}}$ belongs to area $A_{1}$ in Figure 1. The principal then has no reason to induce inefficient effort levels by offering inefficient bonuses. This is the case if the wage floor $w$ is sufficiently low and, in particular, if no wage floor exists $(w=-\infty)$. In the spirit of Holmström (1982), the principal can act as a budget breaker in the team production process that is implied by specialization: She can always install a bonus scheme such that each agent is compensated with the full expected marginal return of his individual contribution to the team output $Y$ (see Lemma 1). However, maximizing the expected residual from the production process instead of the expected team output, the principal offers such bonuses only if she can extract the agents' associated surpluses by sufficiently low fixed wages. Otherwise, i.e., if $w$ is sufficiently high, the well-known trade-off between rent extraction and efficiency leads to a distortion of incentives (see, e.g., Laffont and Martimort (2001)).

Proposition 1 also points out that the relative size of $w$ and $u$ is crucial for the principal's decision whether to induce first-best effort. Notably, $w$ needs to be strictly lower than $u$. In other words, the principal already starts distorting agents' incentives in order to save rent payments when the wage floor is strictly below the reservation utility. Proposition 1 additionally reveals that the relation between firm value and the performance measure is also substantial for attaining the first-best. This is because $R$ depends on the net productivities of the tasks with respect to firm value, $f_{i}^{s}$, and with respect to the performance measure, $g_{i}^{s}$. More specifically, the lower the term $R$, the longer the firstbest will be sustained, i.e., the larger the wage floor can be before the principal optimally distorts incentives. Surprisingly, it turns out that $R$ takes its minimum for an imperfect performance measure $P$ whenever tasks are asymmetric. Thus, under specialization, the principal can benefit from an imperfect performance measure because it may allow her to induce the first-best solution for higher wage floors $w$.

Corollary 1 If the net productivities of the tasks are identical, $f_{1}^{s}=f_{2}^{s}$, then $R$ is minimal for $\frac{g_{1}}{g_{2}}=\frac{f_{1}}{f_{2}}$, i.e., for a perfect performance measure $P$. By contrast, if $f_{1}^{s}>f_{2}^{s}$, then $R$ takes its minimum for $\frac{g_{1}}{g_{2}}=h\left(f_{1}, f_{2}, c_{1}, c_{2}\right)<\frac{f_{1}}{f_{2}}$, i.e., for an imperfect performance measure that overemphasizes task 2 relative to task 1 compared to the tasks' true marginal productivities.

If the tasks differ in their importance to the firm, a distorted performance measure is beneficial because it may enable the principal to avoid rent payments to the agents when 
implementing the bonuses that induce first-best effort, $b_{i}^{S^{*}}=f_{i} / g_{i}$. To understand the intuition, it is helpful to rewrite $R$ as

$$
R=\max \left\{g^{T} e^{S^{*}} \cdot b_{1}^{S^{*}}-c\left(e_{1}^{S^{*}}, 0\right), g^{T} e^{S^{*}} \cdot b_{2}^{S^{*}}-c\left(0, e_{2}^{S^{*}}\right)\right\}
$$

This shows that $R$ is minimal when the agents' expected bonus payments net of effort costs are identical under the first-best solution. Under a perfect performance measure, however, the principal pays identical bonuses to the agents, $b_{1}^{S^{*}}=b_{2}^{S^{*}}$. The reason is that, when firm value $Y$ and the performance measure $P$ are perfectly aligned, it is not necessary to correct the agent's marginal incentives by offering different individual bonuses. Consequently, agent 1's expected bonus net of effort costs is lower than agent 2's because agent 1 incurs higher costs in the more valuable task. As a result, as $w$ increases and the bonuses $b_{i}^{S^{*}}$ are retained, agent 2 earns a rent before agent 1 does. At this point, if the principal uses an imperfect performance measure with $\frac{g_{1}}{g_{2}}<\frac{f_{1}}{f_{2}}$, she can lower agent 2's bonus below that of agent 1 . Then, a situation without rents can be sustained for a larger range of wage floors. In other words, an imperfect performance measure allows to equalize agents' expected payments when, due to the wage floor, the fixed wages $s_{i}$ can no longer serve this purpose.

From Proposition 1, we know that the principal refrains from inducing first-best effort levels once the wage floor is so large that condition (FB) is violated. The next proposition shows that, as the wage floor $w$ continues to increase, at some point the principal switches from specialization to the employment of only one agent.

Proposition 2 There is a threshold $\bar{w} \in(u-R, u]$ such that the principal prefers to hire only one agent if $w \geq \bar{w}$. Thus, $w \geq \bar{w}$ is a sufficient condition for the principal to abandon specialization. Moreover, we have $\bar{w}<u$ for all $u>0$. Hence, the principal gives up specialization already for wage floors that are strictly below any positive reservation utility.

Why is it optimal to hire only one agent as soon as the wage floor $w$ exceeds a certain threshold that is even strictly below the agents' reservation utility? The proof of Proposition 2 shows that, under specialization, the principal does not provide incentives for the less important task 2 whenever $w \geq u$. Consequently, effort in task 2 is zero. This is because $w$ is so large relative to $u$ that both agents earn rents for each pair of positive effort levels or, equivalently, bonuses. Providing incentives for agent 2 is then too costly because each positive bonus $b_{2}$ increases the rent of both agents (compare $\left(\mathrm{II}_{S}\right)$ ) but makes only agent 2 to work harder. Therefore, the principal prefers to exclusively focus on the more important task 1 . It follows immediately that the principal is then 
better off by implementing task exclusion, i.e., she hires only one agent and excludes the less important task from his job. This saves the fixed wage $s=w$ for agent 2 , while everything else remains equal. When these wage cost savings are strictly positive (which is guaranteed if $u>0$ ), the principal's profit with one agent is strictly larger than the profit with two agents. Since the profit functions are continuous in $w$ under each job regime, it then follows that task exclusion dominates specialization for wage floors $w$ that are strictly below $u$. Proposition 2 is related to Proposition 1 in Itoh (1994), which also shows that abandoning specialization may be optimal in a team production environment with two tasks that are substitutes in an agent's cost function. In Itoh (1994), agents are risk averse and the driving force behind Itoh's result is that the principal can decrease risk costs when she hires only one agent. Similarly, in our framework, the principal gives up specialization when agents' rents would be rather large under this job regime.

Proposition 1 and 2 provide sufficient conditions for the optimality and suboptimality of specialization, respectively. The principal should hire two agents if the wage floor is sufficiently small $(w \leq u-R)$, and employ only one agent if the wage floor is sufficiently large $(w \geq \bar{w} \in(u-R, u])$. For intermediate wage floors $w \in(u-R, \bar{w})$, a comparison of the different job designs is highly complex because it is not possible to provide an explicit solution to the principal's problem under specialization. Yet in the next proposition we present a further interesting result, restricting attention to the analytically most tractable case of equally costly and independent tasks $\left(c_{1}=c_{2}=1, c_{12}=0\right)$, zero reservation utility $(u=0)$, and identical wage floors for all job designs $\left(w^{m}=w\right)$.

Proposition 3 Assume that $c_{1}=c_{2}=1, c_{12}=u=0$, and $w=w^{m}$. As soon as $w$ is such that at least one agent receives a rent under the optimal contract for the specialized job regime, the principal prefers to hire only one agent.

Proposition 2 was derived on the grounds that a sufficiently high wage floor $(w \geq u)$ would trigger rent payments to both agents under specialization whenever the principal induces positive effort in both tasks, which is therefore never optimal for the principal. Proposition 3 shows that the principal may actually abandon specialization much earlier, namely, before any of the two agents earns a rent under specialization. ${ }^{21}$ The reason is that there is a range of wage floors for which the principal already distorts incentives under specialization, but does not leave rents to the agents yet.

\footnotetext{
${ }^{21}$ For the general effort cost function $c\left(e_{1}, e_{2}\right)$ from (3) it can be shown that a wage floor never entails the employment of two agents who both earn a rent.
} 


\subsection{Optimality Conditions for Multitasking and Task Exclusion}

In this subsection, we focus on a situation where $w \geq \bar{w}$, i.e., when it is already clear from Proposition 2 that the principal hires only one agent because task exclusion dominates specialization. The question then is whether the principal can improve upon task exclusion by implementing multitasking. If effort was contractible, task exclusion would not be part of the surplus-maximizing contract with one agent, which induces effort $e_{1}^{M^{*}}, e_{2}^{M^{*}}>0$ and profit $\pi^{M^{*}}$ (see Section 2). However, with unobservable effort, the principal can elicit these effort levels only if the performance measure is perfect (Lemma 2). With an imperfect performance measure, excluding task 2 from the job has the advantage that the agent is forced to focus on the more productive task, thereby avoiding a misallocation of effort across tasks. On the downside, however, task 2 is not performed at all. Thus, presumably, the usefulness of the performance measure for effectively directing effort to the different tasks determines the attractiveness of multitasking compared to task exclusion. To measure this quality of the performance measure, we use the concept introduced by Schöttner (2008). ${ }^{22}$ Accordingly, we define the vectors $f^{m}=S f$ and $g^{m}=S g$, were $S$ is a 2x2-matrix with $S^{T} S=C^{-1} \cdot{ }^{23}$ Hence, the vectors $f^{m}$ and $g^{m}$ are the tasks' marginal productivities appropriately weighted by the parameters from the agent's cost function. To understand the intuition, consider the example $f=\frac{1}{2}(1,1)^{T}, g=\frac{1}{2}(1,2)^{T}$, and $c_{12}=0$. Then, the relative overemphasis of task 2 in the performance measure is mitigated as the cost parameter for task $2, c_{2}$, increases. The reason is that cost considerations make the agent direct relatively more effort towards task 1 . Thus, even though $f$ and $g$ do not change, the alignment of $Y$ and $P$ and, consequently, the quality of the performance measure improves. More precisely, the alignment of $Y$ and $P$ is reflected by the angle between the vectors $f^{m}$ and $g^{m}$, which we denote by $\theta$. Consequently, $\cos \theta \operatorname{can}$ serve as a measure of alignment or, equivalently, of how useful the performance measure is for providing incentives. The lower $\cos \theta$, the larger the angle $\theta$ and hence the worse aligned are $Y$ and $P$.

Analogously to vector $f^{s}$, which reflects the tasks' net productivities under specialization, vector $f^{m}$ characterizes the tasks' net productivities under multitasking. We obtain $f^{s}=f^{m}$ in the special case of independent tasks, i.e., if $c_{12}=0$. If $c_{12}>0$, however, $f^{m}$ is different from $f^{s}$ because the former vector has to take into account the increased effort costs under multitasking.

We now investigate how optimal contracting under multitasking is affected by the

\footnotetext{
${ }^{22}$ Baker (2002) proposed this measure of alignment for independent and equally costly tasks (i.e., $c_{12}=0$ and $\left.c_{1}=c_{2}=1\right)$.

${ }^{23}$ See Schöttner (2008, p. 143) for how to compute $S$. For the simple case of independent tasks, $c_{12}=0$, we obtain $S=\left(\begin{array}{ll}c_{1}^{-1 / 2} & 0 \\ 0 & c_{2}^{-1 / 2}\end{array}\right)$.
} 
existence of a wage floor and the degree of alignment of performance measure and firm value. If the principal assigns both tasks to a single agent, her optimization problem is

$$
\begin{gathered}
\max _{e, s, b} f^{T} e-\left(s+g^{T} e \cdot b\right) \\
\text { s.t. } \quad e=C^{-1} g \cdot b \\
s+g^{T} e \cdot b-\frac{1}{2} e^{T} C e \geq u \\
s \geq w^{m}
\end{gathered}
$$

The principal maximizes the expectation of firm value minus wage payments, subject to the agent's incentive-compatibility constraint $\left(\mathrm{IC}_{M}\right)$ (which follows from (12)), his participation constraint $\left(\mathrm{PC}_{M}\right)$, and the wage-floor constraint $\left(\mathrm{WC}_{M}\right) \cdot{ }^{24}$ Recall that the wage floor under multitasking may differ from that under specialization or task exclusion; $w^{m} \geq w$. The following Lemma characterizes the optimal contract under multitasking. To shorten notation, we denote by $\|\cdot\|$ the length of a vector, i.e., $\left\|f^{m}\right\|=\sqrt{\left(f_{1}^{m}\right)^{2}+\left(f_{2}^{m}\right)^{2}}$.

Lemma 3 Define $D:=\frac{1}{2}\left\|f^{m}\right\|^{2} \cos ^{2} \theta$. If the principal hires one agent and assigns both tasks to him, she implements the bonus

$$
b^{M}\left(u, w^{m}\right)= \begin{cases}\frac{\left\|f^{m}\right\|}{\left\|g^{m}\right\|} \cos \theta & \text { if } w^{m} \leq u-D \\ \frac{\sqrt{2\left(u-w^{m}\right)}}{\left\|g^{m}\right\|} & \text { if } u-D<w^{m} \leq u-\frac{D}{4} \\ \frac{1}{2} \frac{\left\|f^{m}\right\|}{\left\|g^{m}\right\|} \cos \theta & \text { if } u-\frac{D}{4}<w^{m}\end{cases}
$$

and earns the expected profit

$$
\pi^{M}\left(u, w^{m}\right)= \begin{cases}D-u & \text { if } w^{m} \leq u-D \\ 2 \sqrt{\left(u-w^{m}\right) D}+w^{m}-2 u & \text { if } u-D<w^{m} \leq u-\frac{D}{4} . \quad\left(\pi^{M}\right) \\ \frac{D}{2}-w^{m} & \text { if } u-\frac{D}{4}<w^{m}\end{cases}
$$

The agent obtains a rent of $w^{m}+\frac{D}{4}-u$ if and only if $u-\frac{D}{4}<w^{m}$.

The optimal bonus and the principal's profit are illustrated in Figure 2 for $u=0 .{ }^{25}$ According to Lemma 3 , the highest bonus $b^{P C}=\frac{\left\|f^{m}\right\|}{\left\|g^{m}\right\|} \cos \theta$ is implemented if a wage floor exists but is rather small $\left(w^{m} \leq u-D\right)$. Then, only the participation constraint $\left(\mathrm{PC}_{M}\right)$ is binding at the optimal solution. By contrast, the principal chooses the lowest bonus $b^{W C}=1 / 2 b^{P C}$ if the wage floor is sufficiently large $\left(u-D / 4<w^{m}\right)$. In this case, only the wage-floor constraint $\left(\mathrm{WC}_{M}\right)$ is binding and, thus, the agent receives a rent. In

\footnotetext{
${ }^{24}$ We neglect the second wage floor constraint $s+b \geq w^{m}$ because from $\left(\mathrm{IC}_{M}\right)$ it is clear that we can focus on non-negative bonuses.

${ }^{25}$ Figure 2 is sketched for $\left(f^{m}\right)^{T} g^{m}=0.8$. If $u$ increases, both curves shift to the right. In addition, $\pi^{M}\left(u, w^{m}\right)$ shifts downwards such that profit is again zero at $w^{m}=\frac{D}{2}$.
} 
particular, an increase in the wage floor raises the agent's rent by exactly this amount, while the principal's profit is reduced by the same amount. However, there also is an interval of intermediate wage floors $\left(u-D<w^{m} \leq u-D / 4\right)$ where both the participation constraint and the wage-floor constraint are binding. For such wage floors, the principal already diminishes incentives but the optimal incentive distortion completely avoids rent payments to the agent. Thus, the wage floor strictly reduces the overall surplus from the relationship without allocating part of the remaining surplus to the agent. ${ }^{26}$

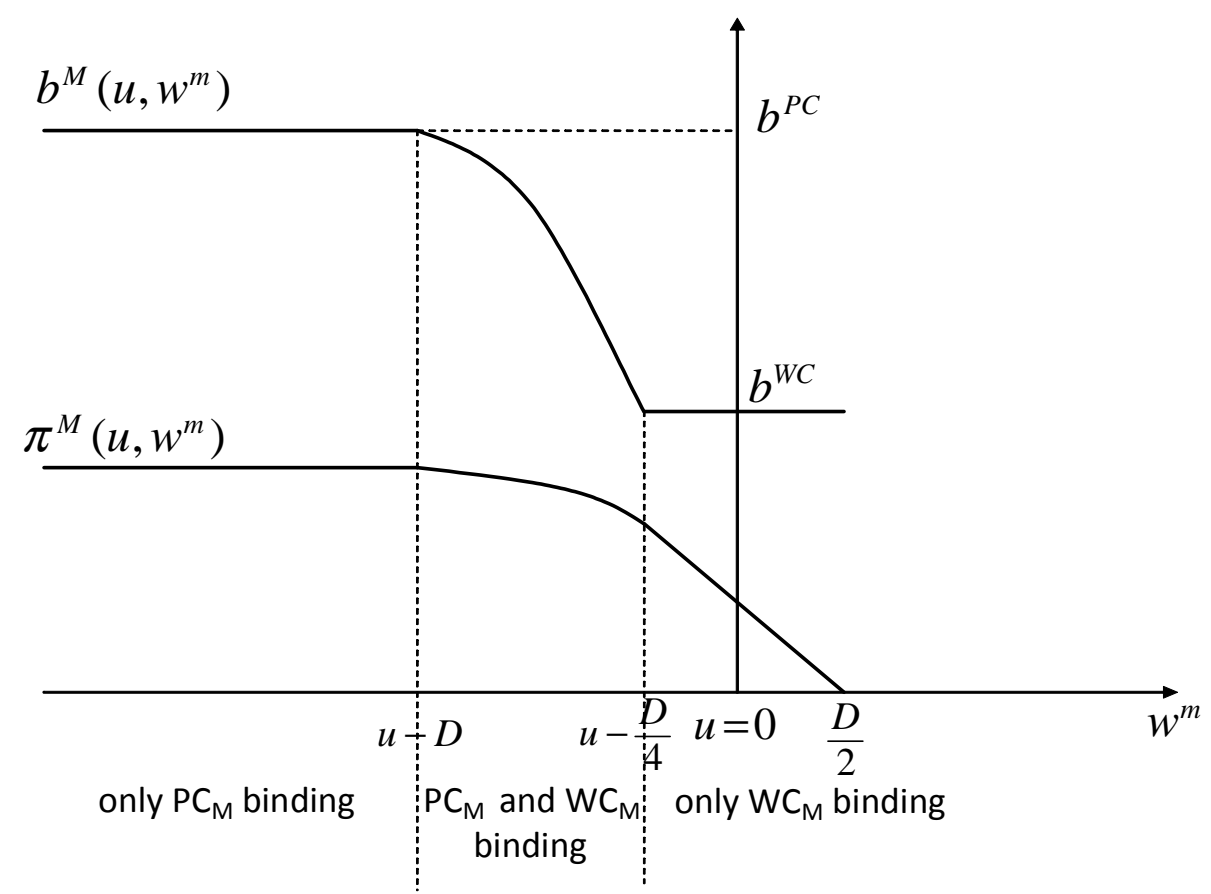

Figure 2: The optimal bonus and profit with one agent and multitasking for $u=0$.

Furthermore, Lemma 3 shows that the principal's profit is increasing in $D$ and, hence, in the alignment between firm value and performance measure, $\cos \theta$. Intuitively, the more useful the performance measure for providing incentives, the higher powered will be the agent's bonus contract. Consequently, the principal's profit increases. In the absence of a wage floor, Schöttner (2008, p. 144) has derived the same result. However, in the given case with a wage floor, a high bonus also implies that the agent is more likely to earn a rent. Thus, the higher $\cos \theta$, the lower the threshold on the wage floor above which a rent is paid to the agent. The maximum surplus $\pi^{M^{*}}=\frac{\left\|f^{m}\right\|^{2}}{2}-u$ is attained only if $\cos \theta=1$ and, additionally, $w^{m}$ is sufficiently small, $w^{m} \leq u-\frac{\left\|f^{m}\right\|^{2}}{2}=-\pi^{M^{*}}$. In particular, this means that the wage floor must be negative. Finally, the profit under multitasking decreases in the degree of task substitutability, $c_{12}$. The reason is that a higher $c_{12}$ diminishes the net productivity of the agent's effort and, moreover, also exacerbates the misallocation of

\footnotetext{
${ }^{26}$ For a detailed discussion of welfare effects of $w$ and $u$ see Section 4.1.
} 
effort across tasks, i.e., both $\left\|f^{m}\right\|$ and $\cos \theta$ decrease. $^{27}$

We now use the results on multitasking to establish the optimal job design when the principal hires only one agent.

Proposition 4 Assume that $w \geq \bar{w}$, i.e., the principal hires only one agent. If a task is excluded from the agent's job, this will always be task 2. (i) If $w^{m}=w$, the principal excludes task 2 if and only if $f_{1}^{s} \geq\left\|f^{m}\right\| \cdot \cos \theta$. Otherwise, the principal assigns both tasks to the agent. (ii) If $w^{m}>w$, a sufficient condition for multitasking is that $f_{1}^{s}<$ $\left\|f^{m}\right\| \cdot \cos \theta$ and $w^{m} \leq \hat{w}$, where $\hat{w}$ is implicitly defined as $\pi^{M}(u, \hat{w})=\frac{1}{2}\left(f_{1}^{s}\right)^{2}-u$.

Proposition 4 shows that, if the principal excludes a task, this will be task 2 , which has the lower net productivity under specialization. In case (i), wage floors are independent of the task assignment. Then, for given net productivities under task exclusion and multitasking, $f_{1}^{s}$ and $f^{m}$, respectively, task 2 should not be performed if the performance measure is sufficiently distortive (i.e., $\cos \theta$ is low). Excluding task 2 then prevents a relatively severe misallocation of effort across tasks by forcing the agent to focus on task 1 only. If, however, the performance measure is perfect $(\cos \theta=1)$, the agent should always carry out both tasks. ${ }^{28}$ On the other hand, holding the alignment of an imperfect performance measure (i.e., $\cos \theta<1$ ) fixed, exclusion of task 2 is optimal if task 1's net productivity, $f_{1}^{s}$, is sufficiently large compared to the two tasks' joint net productivity under multitasking, $\left\|f^{m}\right\|$. Multitasking is then so exhausting for the agent that, in combination with imperfect performance measurement, the principal is better off avoiding it. Moreover, because the profit under multitasking or, equivalently, $\left\|f^{m}\right\| \cdot \cos \theta$ decreases in $c_{12}$, a stronger substitutability between tasks makes multitasking less likely. Finally, whether task exclusion is optimal or not does not depend on $u$ and $w=w^{m}$. This is because these parameters have the same impact on the principal's profit under task exclusion and multitasking.

Now consider case (ii), which occurs if the wage floor is due to an hourly minimum wage and multitasking leads to a longer working time. Then the high wage floor under multitasking may prevent the principal from adopting this job design even if the performance measure is relatively effective, i.e., $f_{1}^{s}<\left\|f^{m}\right\| \cdot \cos \theta$. Multitasking occurs only if $w^{m}$ is not too large $\left(w^{m} \leq \hat{w}\right)$.

To summarize, when the principal hires only one agent, exclusion of the less important task can be optimal for two reasons. First, it forces the agent to focus on the more productive task, thereby avoiding a misallocation of effort across tasks that occurs under multitasking when the performance measure is imperfect. Second, the minimum wage that

\footnotetext{
${ }^{27}$ Schöttner (2008, p.148) provides a formal proof and an intuition.

${ }^{28}$ The inequality $f_{1}^{s}<\left\|f^{m}\right\|$ holds because, by the assumptions made in Section $2, \pi^{M^{*}}=\frac{f^{T} C^{-1} f}{2}-u=$ $\frac{\left(f^{m}\right)^{T} f^{m}}{2}-u=\frac{\left\|f^{m}\right\|^{2}}{2}-u$ is larger than $\frac{\left(f_{1}^{s}\right)^{2}}{2}-u$, the profit under task exclusion.
} 
has to be paid to an agent who works long hours due to multitasking is too large.

\section{Discussion and Extensions}

\subsection{Effects of Changes in the Wage Floor and the Reservation Utility on Welfare and Organizational Design}

Our previous results - in particular those from Proposition 1 and 2 and Lemma 3 - show that the optimal job design, optimal incentive contracts, firm profit, and worker rents crucially depend on the relative size of the reservation utility and the wage floor. This suggests that exogenous changes in the two parameters should affect both the optimal organizational design and total welfare. Interestingly, we can demonstrate that equally directed changes in the reservation utility and the wage floor usually have opposing effects. Opposing effects on welfare are present even if the organizational design cannot be adapted. To see this, assume that the job design is exogenously fixed to multitasking. From Lemma 3 it follows that the expected total surplus from the employment relationship, i.e., the sum of the principal's expected profit and the agent's expected payment net of effort costs, is given by:

$$
\Pi= \begin{cases}D & \text { if } D \leq u-w^{m} \\ 2 \sqrt{\left(u-w^{m}\right) D}-\left(u-w^{m}\right) & \text { if } \frac{D}{4} \leq u-w^{m}<D \\ \frac{3}{4} D & \text { if } u-w^{m}<\frac{D}{4}\end{cases}
$$

Accordingly, $\Pi$ is a function of the difference between the reservation utility and the wage floor, $u-w^{m}$, and is weakly increasing in this difference. $\Pi$ strictly increases in $u-w^{m}$ in the intermediate case $\frac{D}{4} \leq u-w^{m}<D$, where both the agent's participation constraint and the wage floor constraint are binding. A higher reservation utility then enhances welfare because the principal responds to a higher $u$ by raising the bonus, which entails higher total surplus. At the same time, the agent's net payoff increases. By contrast, a marginal increase in the wage floor leads to weaker incentives and lower welfare. It has, however, no effect on the agent's payoff as long as $\frac{D}{4}<u-w^{m}$. The reason for the opposing effects of the two parameters on the total surplus is that they affect the principal's incentive contracting problem in fundamentally different ways: The reservation utility determines the minimum ex-ante expected payment to the agent whereas the wage floor stipulates a lower bound on ex-post payments. When the former increases, the principal is forced to leave a larger share of the expected total surplus to the agent, which she optimally achieves by increasing the bonus and keeping the fixed wage constant. By contrast, if the wage floor increases, the principal has to increase the fixed wage, which she optimally counteracts by lowering the bonus. In the two remaining cases, if $D \leq u-w^{m}$ or $u-w^{m}<\frac{D}{4}$, marginal changes 
in $u$ and $w^{m}$ only have redistributive effects. In the first (second) case, an increase in $u$ $\left(w^{m}\right)$ leads to a redistribution of profit from the principal to the agent via the fixed wage, while marginal changes in $w^{m}(u)$ have no effect at all. Overall, a higher reservation utility weakly increases the expected total surplus from the employment relationship, whereas a higher wage floor weakly diminishes total surplus. Moreover, with an increased wage floor, the agent obtains a strictly larger share of the surplus only if the wage floor is relatively high, i.e., $u-w^{m}<\frac{D}{4}$. Otherwise, the agent's expected payoff is strictly increasing in $u .^{29}$

Importantly, our analysis shows that opposing effects of changes in the reservation utility and the wage floor on welfare persist when the organizational design is endogenous. Moreover, there are also opposing effects on the optimal job design. By Proposition 1 and 2 , respectively, the principal employs the first-best job design, specialization, if $u-w \geq R$ but hires only one agent if $u-w \leq 0$. Thus, a higher wage floor makes specialization less likely, while a sufficiently large reservation utility will lead to specialization. ${ }^{30}$

The foregoing discussion has important implications for the functioning of regulatory labor market instruments. A possible interpretation of the agents' reservation utility are unemployment benefits. Since we consider a one-period model, this is saying that, if the worker rejects the firm's contract offer at the beginning of the period, he cannot find a new job within the same period. This assumption is reasonable if the considered period is sufficiently short and there is some unemployment on the labor market. An example of a wage floor with high empirical and political relevance is the legal minimum wage. The first minimum wage was introduced in the United States in 1938. Although the minimum wage has always been a controversial policy, by now the majority of countries have legally implemented some form of a minimum wage. The commonly stated primary goals of introducing a minimum wage are correcting for market inefficiencies due to, e.g., monopsonistic power or informational asymmetries and reducing earnings inequality and poverty by supporting low-income groups of the population (compare Boeri and van Ours (2008), p. 46). Whether the minimum wage is indeed effective in achieving these goals is

\footnotetext{
${ }^{29} \mathrm{An}$ analogous discussion applies if the job design is fixed to task exclusion. Total surplus is then increasing in $u-w$. Fixing the job design to specialization, we similarly obtain opposing effects of changes in $u$ and $w$. Proposition 1 shows that the first-best total surplus is realized if $u-w$ is sufficiently large, i.e., $u-w \geq R$.

${ }^{30}$ If $u \geq R+w$ and $u$ further increases so that Assumption 1 is finally violated, an increase in the reservation utility still enhances total welfare. The first-best job design is then multitasking but the associated first-best surplus from the employment relationship, $\pi^{M^{*}}+u$, cannot be attained with an imperfect performance measure. For sufficiently low values of $u$, specialization is still the optimal job design because it solves the problem of effort misallocation. The principal, however, abandons specialization when $u$ gets sufficiently large. At this point, the workers are not worse off than under specialization because one of them earns (at least) $u$ in the firm while the dismissed worker obtains the reservation utility outside the firm. By the analysis at the beginning of this subsection, a further increase in $u$ has a positive effect on total welfare.
} 
a matter of frequent discussion and investigation. ${ }^{31}$ Even though our analysis does not allow to draw conclusions at an aggregate level, it contributes to the debate by highlighting possibly distinct consequences of minimum wages and unemployment benefits for organizational design and welfare. In our model, if unemployment benefits are small enough for specialization to maximize total surplus (i.e., Assumption 1 holds) and no minimum wage exists, the firm will choose specialization. The introduction of a minimum wage then has a quite different effect on welfare and work organization than an increase in the unemployment benefit: Establishing a minimum wage that forces the firm to increase workers' fixed wages necessarily implies that the firm induces an inefficient effort allocation and, consequently, welfare decreases. Workers may, however, earn rents due to the minimum wage. Yet the latter may also induce the firm to dismiss one of the workers. Notably, this happens already for a minimum wage below the level of the unemployment benefit (compare Proposition 2). By contrast, a higher unemployment benefit has no effect on effort efficiency and employment as long as the firm still finds it profitable to hire two workers (i.e., Assumption 1 continues to hold). Moreover, a higher unemployment benefit guarantees specialized workers a larger income because it forces the firm to reward workers accordingly.

Thus, from an efficiency perspective, minimum wages may exhibit a major disadvantage relative to labor market instruments stipulating a lower bound on overall expected net payments rather than fixed pay. Moreover, our results imply that the relative size of the wage floor compared to the agents' reservation utility $\left(u-w\right.$ and $u-w^{m}$, respectively) is decisive for optimal job design. In particular, the detrimental effects of the minimum wage may be diminished by good outside opportunities on the side of the workers.

\subsection{Model Extensions}

Complementary Tasks So far, we have focused on a situation where tasks are either independent $\left(c_{12}=0\right)$ or substitutes $\left(c_{12}>0\right)$, i.e., they compete for an agent's attention. However, tasks may also interact in an advantageous way such that the costs of one task decrease if the agent also performs the other one. Tasks are then complements $\left(c_{12}<0\right) .{ }^{32}$ In the introductory fast-food example, serving customers and selling food are presumably complementary tasks whereas cooking and cleaning are likely to be substitutes. With complementary tasks, Assumption 1 does not hold. The first-best job design then is multitasking because total effort costs decrease if both tasks are performed by a single agent

\footnotetext{
${ }^{31}$ For comprehensive overviews of the theory, the politics, and empirical evidence on the minimum wage see, e.g., Card and Krueger (1995) or Neumark and Wascher (2008). A large body of empirical research investigates the overall employment effects of minimum wages at an aggregate level. Yet there is a lack of consensus about its overall impact. For a review see Neumark and Wascher (2007).

${ }^{32}$ Convexity of the cost function requires that $-\sqrt{c_{1} c_{2}}<c_{12}$.
} 
and, moreover, the principal does not have to compensate a second agent for his reservation utility $u$ (i.e., $\pi^{M^{*}}>\pi^{S^{*}}$ ). Nevertheless, with unobservable effort and imperfect performance measurement, the principal still prefers specialization to multitasking in the absence of wage floors if the performance measure is sufficiently distortive and $u$ is not too large. This is the case if the profit under specialization, $\pi^{S^{*}}$, is larger than the profit when employing only one agent, $\max \left\{\pi^{M}(u,-\infty), \frac{1}{2}\left(f_{1}^{s}\right)^{2}-u\right\}$, where the first term in brackets denotes the profit under multitasking and the second one is the profit under task exclusion. Accordingly, specialization is the second-best job design in the absence of wage floors if and only if

$$
u \leq \frac{1}{2}\left(\left\|f^{s}\right\|^{2}-\max \left\{\left\|f^{m}\right\|^{2} \cos ^{2} \theta,\left(f_{1}^{s}\right)^{2}\right\}\right) .
$$

Given that condition (18) holds, our above analysis regarding the effect of an increasing wage floor on the optimal job design continues to apply: The principal implements specialization if $w \leq u-R$ (compare Proposition 1). As $w$ increases above this threshold, at some point the principal switches from specialization to either task exclusion or multitasking (compare Proposition 2). Due to lower effort costs, however, multitasking leads to a higher profit and will be implemented more often compared to a situation where $c_{12} \geq 0 .{ }^{33}$ Our result on the optimality of an imperfect performance measure under specialization (Corollary 1) also continues to hold.

Regarding our discussion of the welfare effects of variations in $u$ and $w$, nothing changes under $c_{12}<0$ when the job design is fixed. When the job design is endogenous and condition (18) holds, $u$ and $w$ have the same opposing effects on the optimal job design as under $c_{12} \geq 0$. Note, however, that first-best welfare will only be realized when the performance measure is perfect, condition (18) does not hold, and the wage floor is sufficiently small ( $w^{m} \leq u-D$, compare Lemma 3$)$. Only then the principal chooses multitasking and induces first-best effort.

Infeasibility of Task Exclusion Furthermore, we assumed that, if the principal hires only one agent, she can exclude one task from the agent's job. However, in some situations, the principal might not be able to control the set of tasks that a single agent engages in. If task exclusion is not feasible, the principal can choose only between specialization or multitasking. ${ }^{34}$ A sufficient condition for the principal to abandon specialization then is that $w$ exceeds the threshold $\bar{w}$ from Proposition 2 and a condition guaranteeing the

\footnotetext{
${ }^{33}$ This is proven in Schöttner (2008, pp. 148-9), where it is shown that $D$ from Lemma 2 and thus $\pi^{M}\left(u, w^{m}\right)$ decreases in $c_{12}$ for $c_{12} \in\left(-\sqrt{c_{1} c_{2}}, \sqrt{c_{1} c_{2}}\right)$.

${ }^{34}$ Under specialization, we assume that it is physically not possible that both agents work on the same task. Thus, if task $i$ is assigned to agent $i$, it is not possible for agent $j \neq i$ to exert effort in task $i$.
} 
optimality of multitasking in Proposition 4 holds. The principal thus still gives up specialization if $w$ is sufficiently large, the quality of the performance measure is not too low, and the multitasking wage floor $w^{m}$ is not too large relative to $w$.

\section{Conclusion}

An important question in organizational and labor economics is how firms can structure jobs efficiently. This paper is the first to present a moral-hazard model that simultaneously considers three important aspects of the firm's job-design problem; asymmetric tasks, imperfect aggregate performance measures, and exogenous wage floors. We show that lower bounds on wages may induce firms to abandon efficient specialized job regimes by redistributing tasks within the organization amongst fewer employees. This not only comes at the cost of inefficient effort incentives but also reduces the number of jobs in the firm. Due to imperfect performance measurement, firms may even entirely exclude less important tasks from the production process. Task exclusion is more likely if tasks differ strongly in their productivity or the aggregate performance measure does only poorly reflect the tasks' true relative productivities. Another important insight of this paper is that the consequences of imperfect performance measurement crucially depend on the organizational form. Regardless of the existence and size of a wage floor, imperfect performance measures are always harmful under multitasking. Under specialization, however, firms may benefit from imperfect performance measurement: When tasks are asymmetric and a wage floor exists, efficiency is sustained longest for an imperfect performance measure that overemphasizes the less productive task appropriately.

Lastly, we show that exogenous changes in market conditions such as workers' reservation utilities and wage floors may have quite different effects on overall welfare and organizational design. In our model, higher reservation utilities usually enhance welfare while higher wage floors entail lower welfare. Of course, practical implications should be considered with care because our model naturally is a simplification of the complex issue of employment, worker motivation, and job design. In particular, we restrict attention to homogeneous agents in our model. If agents are heterogeneous, an increase in reservation utilities or wage floors is likely to entail selection effects that also have to be taken into account, e.g., regarding the productivity of workers who accept the contract. Nevertheless, our results contribute to the discussion of the effectiveness of regulatory labor market instruments such as unemployment benefits and minimum wages by highlighting some practically relevant trade-offs in the presence of moral hazard.

Another implication from our analysis concerns the profitability of investments in performance assessments. Accounting for the fact that monitoring is usually imperfect, the 
paper focuses on the use of one given imperfect team performance measure. In practice, firms can often improve the precision of performance evaluation by spending resources on additional performance measures. Returning to our introductory example, fast-food chains could for instance measure the restaurant's 'cleanliness' in addition to store profits. In this respect, our results imply that the existence of wage floors can make investments in monitoring more profitable for firms. To see this, assume that, in our model, the principal can generate an additional, costly performance measure. In the absence of a wage floor, the principal will nevertheless rely on the imperfect performance measure $P$ and favor specialization. With large wage floors, however, specialization becomes too expensive relative to multitasking in terms of rent payments. While the principal cannot avoid additional effort costs under multitasking, she can solve the problem of effort distortion by using the costly second performance measure. In particular, by appropriately weighting the two performance measures in an incentive contract, she can induce the surplus-maximizing effort pair under multitasking. Hence, the principal invests in a second performance measure whenever the efficiency loss under multitasking due to an imperfect performance measure exceeds the costs of generating the additional performance signal.

Finally, it is worth noting that our results do not hinge on the assumption of risk neutral agents. When agents are risk averse, total risk costs tend to be higher when the principal hires two agents rather than one. Risk aversion thus introduces a comparative disadvantage of specialization in addition to relatively high worker rents in the presence of wage floors. Nevertheless, Proposition 1 in Itoh (1994) suggests that, in the absence of wage floors, specialization is still optimal when the degree of substitutability between tasks is sufficiently high. With a sufficiently high wage floor, the principal will again abandon specialization. Imperfect performance measurement can still have beneficial effects under specialization when it allows to lower an agent's bonus for implementing a given effort level. In fact, since lower bonuses now lead to lower rent payments and lower risk premiums, imperfect performance measurement may become even more advantageous than under risk neutrality. Also, task exclusion continues to constitute an optimal job design when specialization is too costly for the principal and performance measure quality is sufficiently low. If, as discussed above, the principal can invest in a second performance measure, she can benefit from correlation between the two measures when agents are risk averse. Appropriately designed incentive schemes can then be used to lower the agents' exposure to risk, thereby decreasing risk costs. For example, under specialization, the principal can do so by employing interdependent incentive schemes such as team compensation or relative performance pay (see, e.g, Mookherjee (1984) and Holmström and Milgrom (1990)). When only one agent is hired, risk costs may be decreased by appropriately weighting the performance measures in his incentive contract. 


\section{Appendix}

Proof of Proposition 1. For any given effort pair $\left(e_{1}, e_{2}\right)$, the principal's wage payments to the agents must be at least as high as the agents' effort costs and reservation utilities. Thus, an upper bound for the principal's expected profit is given by

$$
\max _{e_{1}, e_{2}} f_{1} e_{1}+f_{2} e_{2}-\frac{1}{2} c_{1} e_{1}^{2}-\frac{1}{2} c_{2} e_{2}^{2}-2 u=\pi^{S^{*}}
$$

This upper bound is attained for $e=e^{S^{*}}=\left(f_{1} / c_{1}, f_{2} / c_{2}\right)^{T}$. By $\left(\operatorname{III}_{S}\right)$, the principal is able to realize this profit if

$$
u+\frac{1}{2} \frac{f_{1}^{2}}{c_{1}} \geq w+\frac{f_{1}^{2}}{c_{1}}+\frac{g_{2}}{g_{1}} \frac{f_{1} f_{2}}{c_{2}} \text { and } u+\frac{1}{2} \frac{f_{2}^{2}}{c_{2}} \geq w+\frac{f_{2}^{2}}{c_{2}}+\frac{g_{1}}{g_{2}} \frac{f_{1} f_{2}}{c_{1}} .
$$

The two inequalities are equivalent to the condition $w \leq u-R$. Thus, if $w \leq u-R$ holds, then $e^{S^{*}}$ is implemented. If $w>u-R$, however, $e^{S^{*}}$ lies in area $A_{2}, A_{3}$, or $A_{4}$ of Figure 1. If $e^{S^{*}}$ lies in the interior of one of these areas, it is straightforward to verify that $e^{S^{*}}$ does not satisfy the first-order conditions for a profit-maximizing effort level in the interior of the respective area. Thus, $e^{S^{*}}$ cannot be a solution to $\left(\mathrm{III}_{S}\right)$. It remains to consider the case where $e^{S^{*}}$ lies on the boundary of $A_{4}$ and $A_{j}, j \in\{2,3\}$. First assume that $e^{S^{*}}$ lies on the boundary of $A_{2}$ and $A_{4}$. Then, inducing $e^{\prime}=\left(f_{1} / c_{1}-\varepsilon, f_{2} / c_{2}\right)^{T}$ with $\varepsilon$ sufficiently close to zero would lead to a higher profit than inducing $e^{S^{*}}$ because the principal's profit is decreasing in $e_{1}$ at $e=e^{S^{*}}$. Similarly, if $e^{S^{*}}$ lies on the boundary of $A_{3}$ and $A_{4}$, the principal prefers $e^{\prime \prime}=\left(f_{1} / c_{1}, f_{2} / c_{2}-\varepsilon\right)^{T}$ to $e^{S^{*}}$.

Proof of Corollary 1. First consider the case $f_{1}^{s}=f_{2}^{s}$. Then,

$$
R=\max \left\{\frac{1}{2}\left(f_{1}^{s}\right)^{2}+\frac{g_{2}^{s}}{g_{1}^{s}} f_{1}^{s} f_{2}^{s}, \frac{1}{2}\left(f_{2}^{s}\right)^{2}+\frac{g_{1}^{s}}{g_{2}^{s}} f_{1}^{s} f_{2}^{s}\right\}
$$

is minimal for $g_{1}^{s}=g_{2}^{s}$. From $f_{1}^{s}=f_{2}^{s}$ and $g_{1}^{s}=g_{2}^{s}$ it follows that $\frac{f_{1}}{f_{2}}=\frac{\sqrt{c_{1}}}{\sqrt{c_{2}}}=\frac{g_{1}}{g_{2}}$ and, hence, the performance measure is perfect. Now consider the case $f_{1}^{s}>f_{2}^{s}$. Define $z:=\frac{g_{2}^{s}}{g_{1}^{s}}$. If $z=1, R$ decreases in $z$ and is lowest if $z$ is such that

$$
\begin{aligned}
\frac{1}{2}\left(f_{1}^{s}\right)^{2}+z f_{1}^{s} f_{2}^{s} & =\frac{1}{2}\left(f_{2}^{s}\right)^{2}+\frac{1}{z} f_{1}^{s} f_{2}^{s} \Leftrightarrow \frac{1}{2}\left(\frac{f_{1}}{f_{2}} \sqrt{\frac{c_{2}}{c_{1}}}-\frac{f_{2}}{f_{1}} \sqrt{\frac{c_{1}}{c_{2}}}\right)=\left(\frac{1}{z}-z\right) \\
& \Leftrightarrow \frac{1}{2}\left(\frac{f_{1}}{f_{2}}-\frac{f_{2}}{f_{1}} \frac{c_{1}}{c_{2}}\right)=\left(\frac{1}{z} \sqrt{\frac{c_{1}}{c_{2}}}-z \sqrt{\frac{c_{1}}{c_{2}}}\right)
\end{aligned}
$$

Define $F:=\frac{f_{2}}{f_{1}}, c:=\frac{c_{1}}{c_{2}}$, and $G:=\frac{g_{2}}{g_{1}}$. The last equation can then be transformed to

$$
\frac{1}{2}\left(\frac{1}{F}-F c\right)=\left(\frac{1}{G}-G c\right)
$$


It holds for

$$
G=\frac{c F^{2}-1+\sqrt{1+14 c F^{2}+c^{2} F^{4}}}{4 c F} .
$$

We have $G>F$ if and only if

$$
\begin{gathered}
c F^{2}-1+\sqrt{1+14 c F^{2}+c^{2} F^{4}}>4 c F^{2} \Leftrightarrow \sqrt{1+14 c F^{2}+c^{2} F^{4}}>3 c F^{2}+1 \\
\Leftrightarrow 1+14 c F^{2}+c^{2} F^{4}>9 c^{2} F^{4}+6 c F^{2}+1 \Leftrightarrow 8 c F^{2}>8 c^{2} F^{4} \\
\Leftrightarrow 1>\frac{c_{1}}{c_{2}}\left(\frac{f_{2}}{f_{1}}\right)^{2} \Leftrightarrow f_{1}^{s}>f_{2}^{s},
\end{gathered}
$$

which is satisfied by assumption. Hence, $R$ is minimal if

$$
G=\frac{g_{2}}{g_{1}}=\frac{c F^{2}-1+\sqrt{1+14 c F^{2}+c^{2} F^{4}}}{4 c F}>\frac{f_{2}}{f_{1}} .
$$

The Corollary thus follows by defining $h\left(f_{1}, f_{2}, c_{1}, c_{2}\right):=\frac{4 c F}{c F^{2}-1+\sqrt{1+14 c F^{2}+c^{2} F^{4}}}$

Proof of Proposition 2. We first show that hiring only one agent (weakly) dominates specialization for all $w \geq u$. If $w \geq u$, the principal's problem $\left(\mathrm{III}_{S}\right)$ can be simplified to

$$
\max _{e_{1}, e_{2}} f_{1} e_{1}+f_{2} e_{2}-c_{1} e_{1}^{2}-c_{2} e_{2}^{2}-\frac{c_{1} g_{2}^{2}+c_{2} g_{1}^{2}}{g_{1} g_{2}} e_{1} e_{2}-2 w
$$

First, consider the case $g_{1}^{s}=g_{2}^{s} \Leftrightarrow g_{1} / g_{2}=\sqrt{c_{1}} / \sqrt{c_{2}}$. Then, $\frac{c_{1} g_{2}^{2}+c_{2} g_{1}^{2}}{g_{1} g_{2}}=2 \sqrt{c_{1} c_{2}}$ and the principal's objective function becomes

$$
\max _{e_{1}, e_{2}} f_{1} e_{1}+f_{2} e_{2}-\left(\sqrt{c_{1}} e_{1}+\sqrt{c_{2}} e_{2}\right)^{2}-2 w
$$

If $f_{1}^{s}=f_{2}^{s}$, every combination of effort levels $\left(e_{1}, e_{2}\right)$ such that $\sqrt{c_{1}} e_{1}+\sqrt{c_{2}} e_{2}=f_{1} /\left(2 \sqrt{c_{1}}\right)$ maximizes the principal's profit. Thus, $e_{1}=f_{1} /\left(2 c_{1}\right)$ and $e_{2}=0$ constitute an optimal effort pair. If $f_{1}^{s}>f_{2}^{s},{ }^{35}$ we have a corner solution with $e_{1}=f_{1} /\left(2 c_{1}\right)$ and $e_{2}=0$. In both cases, the profit is $\pi^{S}(u, w)=\frac{1}{4} \frac{f_{1}^{2}}{c_{1}}-2 w$. Now assume that $g_{1}^{s} \neq g_{2}^{s} \Leftrightarrow \sqrt{c_{2}} g_{1} \neq \sqrt{c_{1}} g_{2}$. Then, $\frac{c_{1} g_{2}^{2}+c_{2} g_{1}^{2}}{g_{1} g_{2}}>2 \sqrt{c_{1} c_{2}}$. Hence, for any given pairs $\left(e_{1}, e_{2}\right)$ and $\left(f_{1}, f_{2}\right)$, the principal's profits are (weakly) lower than for the case $g_{1}^{s}=g_{2}^{s}$. However, the principal can still realize profit $\pi^{S}=\frac{1}{4} \frac{f_{1}^{2}}{c_{1}}-2 w$ by inducing $e_{1}=f_{1} /\left(2 c_{1}\right)$ and $e_{2}=0$. Thus, these effort levels are again optimal. However, the principal can realize a higher profit by hiring only one agent agent, assigning only task 1 to the agent and offering the contract $s=w, b=f_{1} /\left(2 g_{1}\right)$. This also leads to effort levels $e_{1}=f_{1} /\left(2 c_{1}\right), e_{2}=0$, but the profit is $\frac{1}{4} \frac{f_{1}^{2}}{c_{1}}-w \geq \pi^{S}$. If $u>0$, then $w>0$ and hence the inequality is strict. By continuity of the profit functions, specialization is then also dominated for an interval of wage floors strictly below $w$. The proposition thus follows.

\footnotetext{
${ }^{35}$ Recall that $f_{1}^{s} \geq f_{2}^{s}$ by Assumption 1.
} 
Proof of Proposition 3. Due to its length, the proof is excluded from the paper and made available on the authors' websites.

Proof of Lemma 3. To solve the principal's problem, we first use equation $\left(\mathrm{IC}_{M}\right)$ to replace $e$ in the principal's problem and also combine $\left(\mathrm{PC}_{M}\right)$ and $\left(\mathrm{WC}_{M}\right)$, which yields:

$$
\begin{gathered}
\max _{s, b} f^{T} C^{-1} g \cdot b-\left(s+g^{T} C^{-1} g \cdot b^{2}\right) \\
s=\max \left\{u-g^{T} C^{-1} g \cdot \frac{b^{2}}{2}, w^{m}\right\} .
\end{gathered}
$$

Hence, by substituting $s$, the principal's problem can be written as a function of the bonus $b$ only:

$$
\max _{b}\left[f^{T} C^{-1} g \cdot b-\max \left\{u+g^{T} C^{-1} g \cdot \frac{b^{2}}{2}, w^{m}+g^{T} C^{-1} g \cdot b^{2}\right\}\right] .
$$

There are three possible cases. At the optimal solution, either (i) only the participation constraint $\left(\mathrm{PC}_{M}\right)$ is binding, or (ii) only the wage floor constraint $\left(\mathrm{WC}_{M}\right)$ is binding or (iii) both are binding. In case (i), the optimal bonus is

$$
b^{P C}=\frac{f^{T} C^{-1} g}{g^{T} C^{-1} g}=\frac{(S f)^{T}(S g)}{(S g)^{T}(S g)}=\frac{\left(f^{m}\right)^{T} g^{m}}{\left(g^{m}\right)^{T} g^{m}}=\frac{\left\|f^{m}\right\|}{\left\|g^{m}\right\|} \cos \theta
$$

where the last equation follows because $\left(f^{m}\right)^{T} g^{m}=\left\|f^{m}\right\| \cdot\left\|g^{m}\right\| \cdot \cos \theta$ and $\left(g^{m}\right)^{T} g^{m}=$ $\left\|g^{m}\right\|^{2}$. This case occurs if

$$
u-w^{m} \geq \frac{1}{2} g^{T} C^{-1} g \cdot\left(b^{P C}\right)^{2}=\frac{1}{2} \frac{\left(f^{T} C^{-1} g\right)^{2}}{g^{T} C^{-1} g}=\frac{1}{2}\left\|f^{m}\right\|^{2} \cos ^{2} \theta=D .
$$

In case (ii), the optimal bonus is $b^{M W}=1 / 2 \cdot b^{P C}$. It occurs if

$$
u-w^{m}<\frac{1}{2} g^{T} C^{-1} g \cdot\left(\frac{1}{2} b^{P C}\right)^{2}=\frac{1}{8} \frac{\left(f^{T} C^{-1} g\right)^{2}}{g^{T} C^{-1} g}=\frac{1}{4} D .
$$

Finally, case (iii) occurs if $\frac{1}{4} D \leq u-w^{m}<D$ and the bonus is

$$
\hat{b}=\sqrt{\frac{2\left(u-w^{m}\right)}{g^{T} C^{-1} g}}=\frac{\sqrt{2\left(u-w^{m}\right)}}{\left\|g^{m}\right\|} .
$$

By substituting the optimal bonuses in the objective function (34), we obtain the profit function $\pi^{M}\left(u, w^{m}\right)$ given in the Lemma.

Proof of Proposition 4. We first solve the principal's optimization problem under task exclusion and show that, if a task is excluded, this will be task 2. Assume that the agent performs task $i$, while task $j \neq i$ is excluded from the job. Then, the principal's 
optimization problem is

$$
\begin{gathered}
\max _{e_{i}, s, b} f_{i} e_{i}-s-g_{i} e_{i} \cdot b \\
e_{i}=\underset{\widehat{e}_{i}}{\arg \max _{\widehat{e}} s+g_{i} \widehat{e}_{i} \cdot b-\frac{1}{2} c_{i} \widehat{e}_{i}^{2}} \\
s+g_{i} e_{i} \cdot b-\frac{1}{2} c_{i} e_{i}^{2} \geq u \\
s, s+b \geq w
\end{gathered}
$$

This problem can be transformed analogously to the principal's problem under broad task assignment, $\left(\mathrm{I}_{M}\right)-\left(\mathrm{WC}_{M}\right)$, yielding

$$
\max _{b}\left[\frac{f_{i} g_{i}}{c_{i}} \cdot b-\max \left\{u+\frac{1}{2} \frac{g_{i}^{2}}{c_{i}} b^{2}, w+\frac{g_{i}^{2}}{c_{i}} b^{2}\right\}\right] .
$$

The principal optimally implements the bonus

$$
b\left(f_{i}, u, w\right)= \begin{cases}\frac{f_{i}}{g_{i}} & \text { if } w \leq u-\frac{f_{i}^{2}}{2 c_{i}} \\ \frac{\sqrt{2 c_{i}(u-w)}}{g_{i}} & \text { if } u-\frac{f_{i}^{2}}{2 c_{i}}<w \leq u-\frac{f_{i}^{2}}{8 c_{i}} \\ \frac{f_{i}}{2 g_{i}} & \text { if } u-\frac{f_{i}^{2}}{8 c_{i}}<w\end{cases}
$$

and earns the profit

$$
\pi\left(f_{i}, u, w\right)= \begin{cases}\frac{f_{i}^{2}}{2 c_{i}}-u & \text { if } w \leq u-\frac{f_{i}^{2}}{2 c_{i}} \\ \sqrt{\frac{2(u-w)}{c_{i}}} f_{i}+w-2 u & \text { if } u-\frac{f_{i}^{2}}{2 c_{i}}<w \leq u-\frac{f_{i}^{2}}{8 c_{i}} \\ \frac{f_{i}^{2}}{4 c_{i}}-w & \text { if } u-\frac{f_{i}^{2}}{8 c_{i}}<w\end{cases}
$$

Next, we prove that $\pi\left(f_{i}, u, w\right)$ is increasing in $f_{i}$, or, equivalently,

$$
\pi\left(f_{1}, u, w\right) \geq \pi\left(f_{2}, u, w\right) \text { for all } w, \text { holding } u \text { constant. }
$$

Inequality (46) obviously holds for $w \leq u-\frac{f_{1}^{2}}{2 c_{1}}, u-\frac{f_{2}^{2}}{2 c_{2}}<w \leq u-\frac{f_{1}^{2}}{8 c_{1}}$, and $u-\frac{f_{2}^{2}}{8 c_{2}}<w$. Now consider the case $w \in\left(u-\frac{f_{1}^{2}}{2 c_{1}}, u-\frac{f_{2}^{2}}{2 c_{2}}\right]=A$. Since $\pi$ is continuous in $w$, we have $\pi\left(f_{1}, u, u-\frac{f_{2}^{2}}{2 c_{2}}\right) \geq \pi\left(f_{2}, u, u-\frac{f_{2}^{2}}{2 c_{2}}\right)$. Furthermore, $\pi\left(f_{1}, u, w\right)$ is strictly decreasing in $w$ on the interval $A$ while $\pi\left(f_{2}, u, w\right)$ is constant. Thus, (46) holds on the entire interval $A$. Finally, consider the case $w \in\left(u-\frac{f_{1}^{2}}{8 c_{1}}, u-\frac{f_{2}^{2}}{8 c_{2}}\right]=B$. Inequality (46) holds for $w=u-\frac{f_{1}^{2}}{8 c_{1}}$ and $w=u-\frac{f_{2}^{2}}{8 c_{2}}$. Thus, because both $\pi\left(f_{1}, u, w\right)$ and $\pi\left(f_{2}, u, w\right)$ are strictly decreasing in $w$ on $B,(46)$ holds on the entire interval $B$. Therefore, (46) always holds and the principal prefers exclusion of task 2 to exclusion of task 1.

We now prove part (i). If $w^{m}=w$, the principal prefers exclusion of task 2 to broad task 
assignment if $\pi\left(f_{1}, u, w\right) \geq \pi^{M}(u, w)$. Comparing $\left(\pi^{M}\right)$ and (45), using that $\pi\left(f_{1}, u, w\right)$ is increasing in $f_{1}$, yields that exclusion of a task is optimal if and only if $\frac{f_{1}^{2}}{2 c_{1}} \geq D=$ $\frac{1}{2}\left\|f^{m}\right\|^{2} \cos ^{2} \theta$ or $f_{1}^{s} \geq\left\|f^{m}\right\| \cdot \cos \theta$. Now consider part (ii). If $f_{1}^{s}<\left\|f^{m}\right\| \cdot \cos \theta$, we have $\pi\left(f_{1}, u, w\right)<\pi^{M}(u, w)$. By (45), the highest possible profit under task exclusion is $\frac{1}{2}\left(f_{1}^{s}\right)^{2}-u$. Thus, because $\pi^{M}(u, w)$ is decreasing in $w$, multitasking is optimal for all wage floors $w \leq \hat{w}$, where $\pi^{M}(u, \hat{w})=\frac{1}{2}\left(f_{1}^{s}\right)^{2}-u$. Note that $\hat{w}>u-\frac{f_{i}^{2}}{2 c_{i}}$.

\section{References}

Abowd, J. M., F. Kramarz, and D. N. Margolis (1999). Minimum wages and youth employment in France and the United States. In D. Blanchflower and R. Freeman (Eds.), Youth Employment and Joblessness in Advanced Countries, pp. 427-472. University of Chicago Press.

Amine, S. and P. Lages Dos Santos (2011). The influence of labour market institutions on job complexity. Research in Economics 65(3), 209 - 220.

Baker, G. P. (1992). Incentive contracts and performance measurement. Journal of Political Economy 100(3), 598-614.

Baker, G. P. (2002). Distortion and risk in optimal incentive contracts. Journal of Human Resources 37(4), 728-751.

Boeri, T. and J. van Ours (2008). Economics of Imperfect Labor Markets. Princeton University Press.

Card, D. and A. B. Krueger (1995). Myth and Measurement: The New Economics of the Minimum Wage. Princeton, New Jersey: Princeton University Press.

Currie, J. and B. C. Fallick (1996). The minimum wage and the employment of youth: Evidence from the NLSY. Journal of Human Resources 31, 404-428.

Datar, S., S. Kulp, and R. Lambert (2001). Balancing performance measures. Journal of Accounting Research 39, 75-92.

Demougin, D. and C. Fluet (2001). Monitoring versus incentives. European Economic Review 45(9), 1741-1764.

Duff, C. (1996, November 20). New minimum wage makes few waves. The Wall Street Journal, A2.

Feltham, G. A. and J. Xie (1994). Performance measure congruity and diversity in multi-task principal/agent relations. Accounting Review 69(3), 429-453.

Gibbons, R. (2005). Incentives between firms (and within). Management Science 51(1), $2-17$.

Holmström, B. (1982). Moral hazard in teams. The Bell Journal of Economics 13(2), 324-340.

Holmström, B. and P. Milgrom (1990). Regulating trade among agents. Journal of Institutional and Theoretical Economics 146(1), 85-105.

Holmström, B. and P. Milgrom (1991). Multitask principal-agent analyses: Incentive contracts, asset ownership, and job design. Journal of Law, Economics, and Organization 7, Special Issue, 24-52.

Hoyland, C. (2010a, May 6). Popeyes franchisee says incentive program pays off. Retrieved August 19, 2010 from http://www.qsrweb.com/article/95383/ Popeyes-franchisee-says-incentive-program-pays-off. 
Hoyland, C. (2010b, May 2). Popeyes: Improving the experience. Retrieved August 19, 2010 from http://www.qsrweb.com/article/95441/ Popeyes-Improving-the-experience.

Hughes, J. S., L. Zhang, and J. Xie (2005). Production externalities, congruity of aggregate signals, and optimal task assignments. Contemporary Accounting Research 22, $393-408$.

Itoh, H. (1994). Job design, delegation and cooperation: A principal-agent analysis. European Economic Review 38, 691-700.

Itoh, H. (2001). Job design and incentives in hierarchies with team production. Hitotsubashi Journal of Commerce and Management 36, 1-17.

Jewitt, I., O. Kadan, and J. M. Swinkels (2008). Moral hazard with bounded payments. Journal of Economic Theory 143(1), 59 - 82.

Job-Applications.com (2012). Popeyes Chicken \& Biscuits Employee Job Benefits. Retrieved November 29, 2012, from http://www.job-applications.com/ popeyes-benefits.

Kerr, S. (1975). On the folly of rewarding A, while hoping for B. The Academy of Management Journal 18(4), 769-783.

Kim, S. K. (1997). Limited liability and bonus contracts. Journal of Economics 83 Management Strategy 6(4), 899-913.

Laffont, J.-J. and D. Martimort (2001). The Theory of Incentives. Princeton, New Jersey: Princeton University Press.

Laux, C. (2001). Limited-liability and incentive contracting with multiple projects. RAND Journal of Economics 32, 514-526.

Lewis, T. R. and D. E. Sappington (2000). Contracting with wealth-constrained agents. International Economic Review 41(3), 743-767.

Lewis, T. R. and D. E. Sappington (2001). Optimal contracting with private knowledge of wealth and ability. Review of Economic Studies 68(1), 21-44.

Manning, A. (2003). Monopsony in Motion: Imperfect Competition in Labor Markets. Princeton University Press.

Manning, A. (2010). Imperfect competition in the labour market. CEP Discussion Paper No. 981. Centre for Economic Performance, London School of Economics and Political Science.

McDonald's (2012). Pay and Rewards. Retrieved November 29, 2012, from McDonald's Website: http://www.aboutmcdonalds.com/mcd/corporate_careers/benefits/ highlights_of_what_we_offer/pay_and_rewards.html.

Mookherjee, D. (1984). Optimal incentive schemes with many agents. The Review of Economic Studies 51(3), 433-446.

Neumark, D. and W. L. Wascher (2007). Minimum wages and employment. IZA discussion paper No. 2570.

Neumark, D. and W. L. Wascher (2008). Minimum Wages. Massachusetts Institute of Technology.

Park, E.-S. (1995). Incentive contracting under limited liability. Journal of Economics 83 Management Strategy 4(3), 477-490.

Portugal, P. and A. R. Cardoso (2001). Disentangling the minimum wage puzzle: An analysis of worker accessions and separations. Journal of the European Economic Association 4(5), 988-1033. 
Ratto, M. and W. Schnedler (2008). Too few cooks spoil the broth: Division of labour and directed production. The B.E. Journal of Economic Analysis \& Policy 8(1), Article 27.

Sappington, D. E. (1983). Limited liability contracts between principal and agent. Journal of Economic Theory 29(1), 1-21.

Schmitz, P. W. (2005). Allocating control in agency problems with limited liability and sequential hidden actions. RAND Journal of Economics 36(2), 318-336.

Schnedler, W. (2008). When is it foolish to reward for A while benefiting from B. The Journal of Labor Economics 26(4), 595-619.

Schnedler, W. (2010). Hidden action, identification, and organization design. IZA Discussion Papers 5325, Institute for the Study of Labor (IZA).

Schöttner, A. (2008). Relational contracts, multitasking, and job design. Journal of Law, Economics and Organization 24(1), 138-162.

Wysocki Jr., B. (1997, October 27). Chicken feed - minimum wage is up, but a fast-food chain notices little impact. The Wall Street Journal, A1.

Zavodny, M. (2000). The effect of the minimum wage on employment and hours. Labour Economics 7, 729-750.

Zhang, L. (2003). Complementarity, task assignment, and incentives. Journal of Management Accounting Research 15, 225-246. 